\title{
Principled Artificial Intelligence: Mapping Consensus in Ethical and Rights-based Approaches to Principles for Al
}

\section{Citation}

Fjeld, Jessica, Nele Achten, Hannah Hilligoss, Adam Nagy, and Madhulika Srikumar. "Principled Artificial Intelligence: Mapping Consensus in Ethical and Rights-based Approaches to Principles for Al." Berkman Klein Center for Internet \& Society, 2020.

\section{Permanent link}

http://nrs.harvard.edu/urn-3:HUL.InstRepos:42160420

\section{Terms of Use}

This article was downloaded from Harvard University's DASH repository, and is made available under the terms and conditions applicable to Other Posted Material, as set forth at http:// nrs.harvard.edu/urn-3:HUL.InstRepos:dash.current.terms-of-use\#LAA

\section{Share Your Story}

The Harvard community has made this article openly available. Please share how this access benefits you. Submit a story. 
ARTIFICIAL

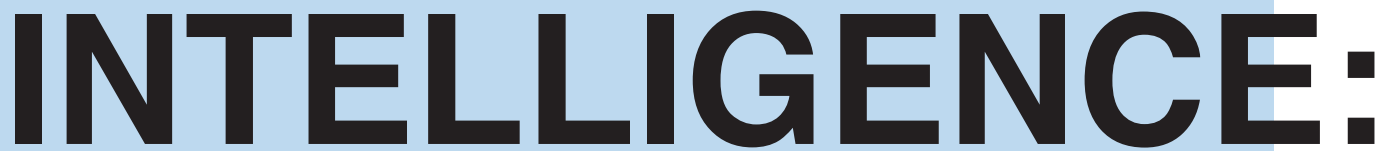

Mapping Consensus in Ethical and Rights-based Approaches to Principles for Al

Jessica Fjeld, Nele Achten, Hannah Hilligoss, Adam Christopher Nagy, Madhulika Srikumar 


\section{Table of Contents}

2 Acknowledgements

1. 3 Introduction

4 Executive Summary

7 How to Use these Materials

8 Data Visualization

2. 11 Definitions and Methodology

11 Definition of Artificial Intelligence

12 Definition of Relevant Documents

14 Document Search Methodology

15 Principle and Theme Selection Methodology

18 Timeline Visualization

3. 20 Themes among Al Principles

3.121 Privacy

28 Accountability

3.3 37 Safety and Security

$3.4 \quad 41$ Transparency and Explainability

47 Fairness and Non-discrimination

3.6 53 Human Control of Technology

3.7 56 Professional Responsibility

3.8 60 Promotion of Human Values

4. 64 International Human Rights

5. 66 Conclusion

6. 68 Bibliography 


\section{Acknowledgements}

This report, Principled Artificial Intelligence: Mapping Consensus in Ethical and Rights-based Approaches to Principles for Al, is part of the Berkman Klein Center for Internet \& Society research publication series. The report and its authors have significantly benefitted from more than two years of research, capacity building, and advocacy executed by the Berkman Klein Center as co-leader of the Ethics and Governance of Artificial Intelligence Initiative in partnership with the MIT Media Lab. Through the Initiative, the Center has worked on pressing issues raised by the development and deployment of Al-based systems - including groundbreaking research on automation's impact on the online media landscape; fostering the growth of inclusive Al research and expertise in academic centers across the globe; and advocating for increased transparency surrounding the use of algorithms in criminal justice decision-making. Notably, the Center engages both private-sector firms and public policymakers in troubleshooting related legal, social, and technical challenges, and has consulted on the development of Al governance frameworks with national governments and intergovernmental bodies, such as the UN High-Level Committee on Programmes and the OECD's Expert Group on Al. Principled Artificial Intelligence has been influenced by these collaborative, multistakeholder efforts, and hopes to contribute to their continued success

The report's lead author, Jessica Fjeld, is the assistant director of the Harvard Law School Cyberlaw Clinic, based at the Center; Nele Achten is an affiliate; Hannah Hilligoss a former Senior Project Coordinator and current HLS JD candidate; Adam Nagy a current Project Coordinator; and Madhulika Srikumar a former Cyberlaw Clinic student and current HLS LLM candidate. Thank you to Amar Ashar, Christopher Bavizz, Zyan Budish, Rob Faris, Urs Gasser, Vivek Krishnamuthy, Momin Malk, Jonathan Zitrain, and others in the Berkman Klein community for their genorous inpul, support, and questions

Thank you to Maia Levy Daniel, Joshua Feldman, Justina He, and Sally Kagay for indispensable research assistance, and to Jessica Dheere, Fanny Hidvégi, Susan Hough, K.S. Park, and Eren Sozuer for their collegial engagement on these issues and this project, as well as to all the individuals and organizations who contributed comments on the draft data visualization we released in summer 2019. An updated and final data visualization accompanies this report: thank you to Melissa Axelrod and Arushi Singh for their thoughtfulness and significant skill in its production.

\section{Introduction}

Alongside the rapid development of artificial intelligence (Al) technology, we have witnessed a proliferation of "principles" documents aimed at providing normative guidance regarding Al-based systems. Our desire for a way to compare these documents - and the individual principles they contain - side by side, to assess them and identify trends, and to uncover the hidden momentum in a fractured, global conversation around the future of $\mathrm{Al}$, resulted in this white paper and the associated data visualization.

It is our hope that the Principled Artificial Intelligence project will be of use to policymakers, advocates, scholars, and others working on the frontlines to capture the benefits and reduce the harms of Al technology as it continues to be developed and deployed around the globe. 


\section{Executive Summary}

In the past several years, seemingly every organization with a connection to technology policy has authored or endorsed a set of principles for Al. As guidelines for ethical rights-respecting, and socially beneficial Al develop in tandem with - and as rapidly as the underlying technology, there is an urgent need to understand them, individually and in context. To that end, we analyzed the contents of thirty-six prominent Al principles documents, and in the process, discovered thematic trends that suggest the earliest emergence of sectoral norms.

While each set of principles serves the same basic purpose, to present a vision for the governance of Al, the documents in our dataset are diverse. They vary in their intended audience, composition, scope, and depth. They come from Latin America, East and South Asia, the Middle East, North America, and Europe, and cultural differences doubtless impact their contents. Perhaps most saliently, though, they are authored by different actors: governments and intergovernmental organizations, companies, professional associations, advocacy groups, and multi-stakeholder initiatives. Civil society and multistakeholder documents may serve to set an advocacy agenda or establish a floor for ongoing discussions. National governments' principles are often presented as part of an overall national Al strategy. Many private sector principles appear intended to govern the authoring organization's internal development and use af Al technology, as well as to communicate its goals to other revent including customers and regulators. Given the range of variation across numolders it's all the more surprising thatar our common themes.

The first substantial aspect of our findings are the eight key themes themselves:

Privacy. Principles under this theme stand for the idea that Al systems should respect individuals' privacy, both in the use of data for the development of technological systems and by providing impacted people with agency over their data and decisions made with it. Privacy principles are present in $97 \%$ of their data and decisions mad

Accountability. This theme includes principles concerning the importance of mechanisms to ensure that accountability for the impacts of Al systems is appropriately distributed, and that adequate remedies are provided. Accountability principles are present in $97 \%$ of documents in the dataset.

- Safety and Security. These principles express requirements that Al systems be safe, performing as intended, and also secure, resistant to being compromised by unauthorized parties. Safety and Security principles are present in $81 \%$ of documents in the dataset.
Transparency and Explainability. Principles under this theme articulate requirements that Al systems be designed and implemented to allow for oversight, including through translation of their operations into intelligible outputs and the provision of information about where, when, and how they are being used. Transparency and Explainability principles are present in $94 \%$ of documents in the dataset.

Fairness and Non-discrimination. With concerns about Al bias already impacting individuals globally, Faimess and Non-discrimination principles call for Al systems individuas ge do to be designed and used to max

Human Control of Technology. The principles under this theme require that important decisions remain subject to human review. Human Control of Technology principles are present in $69 \%$ of documents in the dataset.

Professional Responsibility. These principles recognize the vital role that individuals involved in the development and deployment of Al systems play in the instems systoms' in pacts, and callon ther profesion or. Professiona Responsibility principles are present in $78 \%$ of documens in the dataset.

- Promotion of Human Values. Finally, Human Values principles state that the ends to which Al is devoted, and the means by which it is implemented, should correspond with our core values and generally promote humanity's well-being. Promotion of Human Values principles are present in $69 \%$ of documents in the dataset.

The second, and perhaps even more striking, side of our findings is that more recent documents tend to cover all eight of these themes, suggesting that the conversation around principled $\mathrm{Al}$ is beginning to converge, at least among the communities responsible for the development of these documents. Thus, these themes may represent the "normative core" of a principle-based approach to Al ethics and governance. ${ }^{1}$

However, we caution readers against inferring that, in any individual principles document, broader coverage of the key themes is necessarily better. Context matters. Principles should be understood in their cultural, linguistic, geographic, and organizational context, and some themes will be more relevant to a particular context and audience than others. Moreover, principles are a starting place for governance, not an end. On its own, a set of principles is unlikely to be more than gently persuasive. Its impact is likely to depend on how it is embedded in a larger governance ecosystem, including for instance relevant policies (e.g. Al national plans), laws, regulations, but also professional practices and everyday routines. 
One existing governance regime with significant potential relevance to the impacts of Al systems is international human rights law. Scholars, advocates, and professionals have increasingly been attentive to the connection between Al governance and human rights laws and norms, ${ }^{2}$ and we observed the impacts of this attention among the principles documents we studied. $64 \%$ of our documents contained a reference to human rights, and five documents took international human rights as a framework for their overall effort. Existing mechanisms for the interpretation and protection of human rights may well provide useful input as principles documents are brought to bear on individuals cases and decisions, which will require precise adjudication of standards like "privacy" and "fairness," as well as solutions for complex situations in which separate principles within a single document are in tension with one another.

The thirty-six documents in the Principled Artificial Intelligence were curated for variety, with a focus on documents that have been especially visible or influential. As noted above, a range of sectors, geographies, and approaches are represented. Given our subjective sampling method and the fact that the field of ethical and rights-respecting $\mathrm{Al}$ is still very much emergent, we expect that perspectives will continue to evolve beyond those reflected here. We hope that this paper and the data visualization that accompanies it can be a resource to advance the conversation on ethical and rightsrespecting Al.

\section{How to Use these Materials}

\section{Data Visualization}

The Principled Al visualization, designed by Arushi Singh and Melissa Axelrod, is arranged like a wheel. labed with the sponsoring actors, date, and place of origin. The on exception is th the OECD and $\mathrm{s} 20$ docing text of the principles in these two documents is identica ${ }^{3}$ The spokes are, sorted first alphabetically by the actor type and then by date, from earliest to most recent.

Inside the wheel are nine rings, which represent the eight themes and the extent to which each document makes reference to human rights. In the theme rings, the dot at the intersection with each spoke indicates the percentage of principles falling under the theme that the document addresses: the larger the dot, the broader the coverage. Because each theme contains different numbers of principles (ranging from three to ten), it's instructive to compare circle size within a given theme, but not between then

In the human rights ring, a diamond indicates that the document references human rights or related international instruments, and a star indicates that the document uses international human rights law as an overall framework. 


\section{PRINCIPLED}

\section{ARTIFICIAL INTELLIGENCE}

A Map of Ethical and Rights-Based Approaches to Principles for Al

Authors: Jessica Fjeld, Nele Achten, Hannah Hilligoss, Adam Nagy, Machulika Srikumar

Designers: Arushi Singh (arushisingh.net) and Melissa Axelrod (melissaaxelrod.com)

\section{HOW TO READ:}

Document Title

COVERAGE OF THEMES:

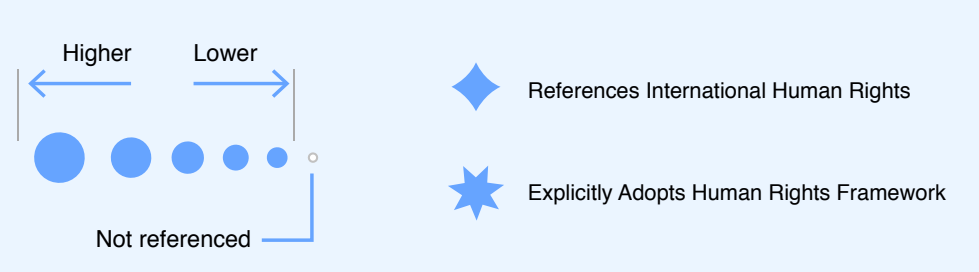

The size of each dot represents the percentage of principles in that theme contained in the
document Since the number of rrinciples per theme varies it's intormative to compare dot sizes document. Since the number of prinipiles
within a ther theme but varies, it's intormative to compare dot sizes

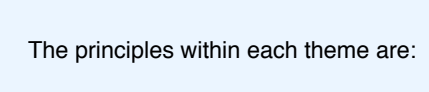

Privacy:
Privacy

Privacy
Control over Use of Data

Consent
Privacy by Design
Recenthe

Recommendation for Data Protection Laws

Ability to Restricic Processing
Right to Rectification

Right to Rectification
Right to Erasure

Accountability:
Accountability

Accountability
Recommendation for New Regulations
Impact Assessment

Impact Assessment
Evaluation and Auditing Requirem

Verifiability and Replicability
Liability and Legal Responsibility

Liability and Legel
Ability to Appeal
Envirinmental

Ability to Appeal
Cnivonmental Responsibility
Creation of a Monitoring Body

Remedy for Automated Decision

Safety and Security
Security

Security
Safety and Reliability
Predictability

Predictability
Security by Design
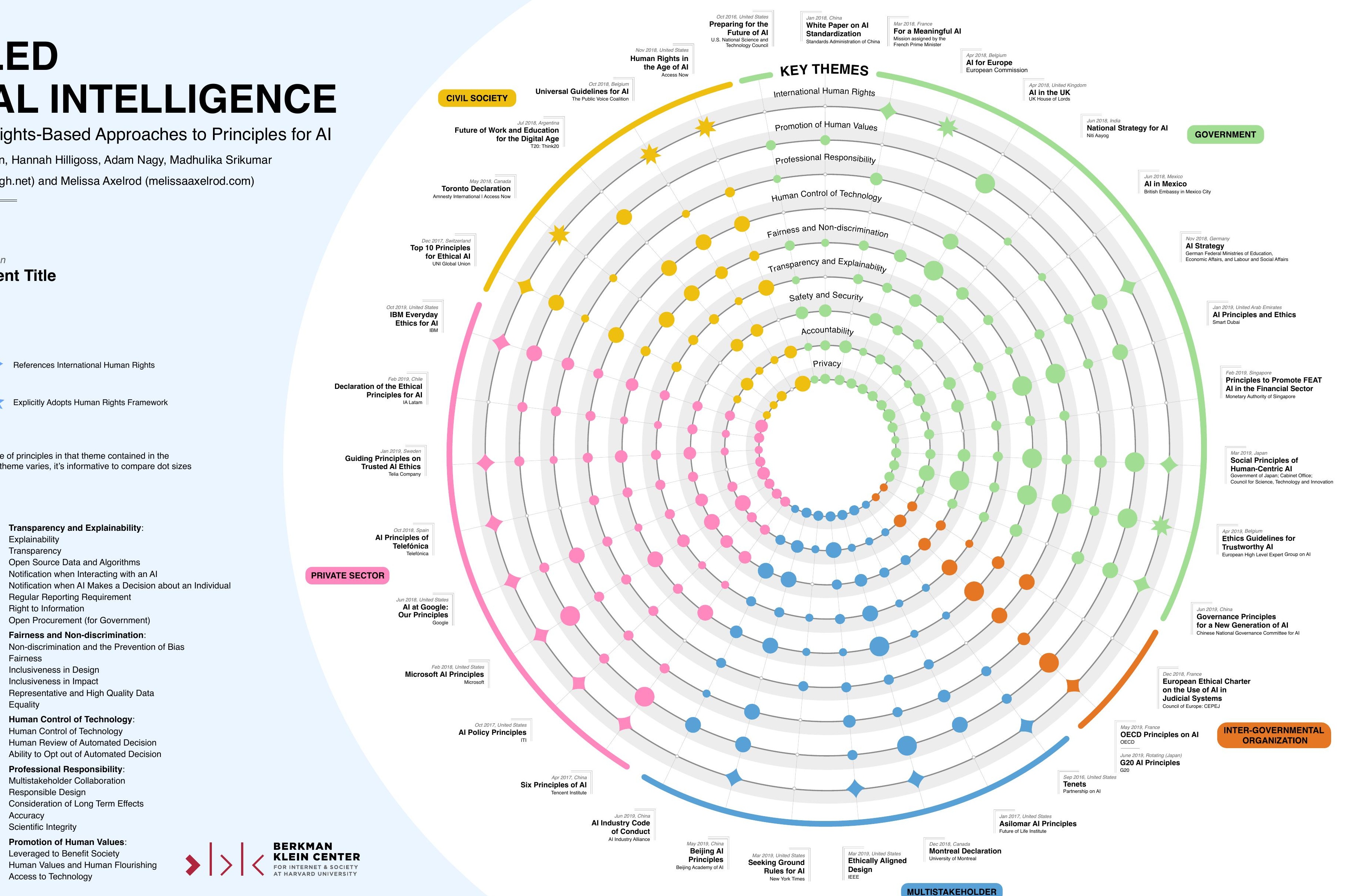
White Paper

Much as the principles documents underlying our research come from a wide variety of stakeholders in the ongoing conversation around ethical and rights-respecting Al, so too we expect a variety of readers for these materials. It is our hope that they will be useful to policymakers, academics, advocates, and technical experts. However, different

groups may wish to engage with the white paper in different ways:

Those looking for a high-level snapshot of the current state of thinking in the governance of Al may be best served by reviewing the data visualization

(p. 8), and reading the Executive Summary (p. 4) and Human Rights section

(p. 64), dipping into the discussion of themes (beginning p. 20) only where they are necessary to resolve a particular interest or question.

- Those looking to do further research on Al principles will likely find the discussions of the themes and principles (beginning p. 20) and Human Rights section (p. 64) most useful, and aris alsoinvitec underlying data.

- Those tasked with drafting a new set of principles may find that the data visualization (p. 8) and discussions of the themes and principles within them (beginning p. 20) can function to offer a head start on content and approaches thereto, particularly as references to existing principles that are most likely to be useful source materia.

- Those seeking closer engagement with primary source documents may variously find the data visualization (p. 8), timeline (p. 18), or bibliography (p. 68) to act as a helpful index.

\section{Definitions and Methodology}

\section{Definition of Artificial Intelligence}

The definition of artificial intelligence, or "Al", has been widely debated over the years, in part because the definition changes as technology advances. ${ }^{4}$ In collecting our dataset, we did not exclude documents based on any particular definition of Al. Rather, we included documents that refer specifically to Al or a closely equivalent term (for example, IEEE uses "autonomous and intelligent systems"). ${ }^{5}$ In keeping with the descriptive approach we have taken in this paper, we'll share a few definitions found in our dataset. The European Commission's High-Level Expert Group on Artificial Intelligence offers a good place to start:

"Artificial intelligence (Al) systems are software (and possibly also hardware) systems designed by humans that, given a complex goal, act in the physical or digital dimension by perceiving their environment through data acquisition, interpreting the collected structured or unstructured data, reasoning on the knowledge, or processing the information, derived from this data and deciding the best action(s) to take to achieve the given goal. Al systems can either use symbolic rules or learn a numeric model, and the can also adapt their behaviour by analysing how the environment is affected by their previous actions." 6

Aspects of this definition are echoed in those found in other documents. For example, some documents define $\mathrm{Al}$ as systems that take action, with autonomy, to achieve a predefined goal, and some add that these actions are generally tasks that would otherwise require human intelligence. 
Other documents define Al by the types of tasks Al systems accomplish - like "learning reasoning, adapting, and performing tasks in ways inspired by the human mind," ${ }^{\text {" }}$ or by its sub-fields like knowledge-based systems, robotics, or machine learning. ${ }^{9}$

\section{Definition of Relevant Documents}

\section{While all of the documents use the term "Al" or an equivalent, not all use the term}

"principles," and delineating which documents on the subject of ethical or rights-respecting Al should be considered "principles" documents was a significant challenge. Our workin definition was that principles are normative (in the sense that lawyers use this term) declarations about how Al generally ought to be developed, deployed, and governed. While the intended audience of our principles documents varies, they all endeavor to shape behavior of an audience - whether internal company principles to follow in Al development or broadly targeted principles meant to further develop societal norms about AI.

Because a number of documents employed terminology other than "principles" while otherwise conforming to this definition, we included them..$^{10}$ The concept of "ethical principles" for Al has encountered pushback both from ethicists, some of whom object to the imprecise usage of the term in this context, as well as from some human rights practitioners, who resist the recasting of fundamental human rights in this language. Rather than disaggregate Al principles from the other structures (international human rights, domestic or regional regulations, professional norms) in which they are intertwined, our research team took pains to assess principles documents in context and to flag external frameworks where relevant. In doing so, we drew inspiration from the work of Urs Gasser, Executive Director of the Berkman Klein Center for Internet \& Society and Professor of Practice at Harvard Law School, whose theory on "digital constitutionalism" describes the significant role the articulation of principles by a diverse set of actors might play as part of the "protonorms.

Our definition of principles excluded documents that were time-bound in the sense of observations about advances made in a particular year ${ }^{11}$ or goals to be accomplished over a particular period. It also excluded descriptive statements about Al's risks and bed ofis. For example, there are numerous compelling reports that assess or comment on the ethical implications of Al, some even containing recommendations for next steps, that don't advance a particular set of principles ${ }^{12}$ and were thus excluded from this dataset. However where a report includec we included that section (but not the rest of the report) in our dataset, ${ }^{13}$ and more generally, when only a certain page range from a broader document conformed to our definition, we limited our sample to those pages. The result of these choices is a narrower set of documents that we hope lends itself to side-by-side comparison, but notably excludes some significant literature.

We also excluded documents that were formulated solely as calls to a discrete further action, for example that that funding be committed, new agencies established, or additional research done on a particular topic, because they function more as a policy objective than a principle. By this same logic, we excluded national Al strategy documents that call for the creation of principles without advancing any ${ }^{14}$ However. where documents otherwise met our definition but contained individual principles such as calls for further research or rour definiton but contained individual principles such Section 32) we did include them. We also included the principle that theme, see and imp 3.2), we did Al should routinely consider the long-term effects of their work (under and implementing Al should routinely consider the long term effects of their work (under Profes for call for further consideration funclions as a principle in that

Finally, we excluded certain early instances of legislation or regulation which closely correspond to our definition of principles. ${ }^{15}$ The process underlying the passage of
governing law is markedly different than the one which resulted in other principles documents we were considering, and we were conscious of the fact that the goal of this project was to facilitate side-by-side comparison, and wanted to select documents that could fairly be evaluated that way. For the same reason, we excluded documents that looked at only a specific type of technology, such as facial recognition. We found that the content of principles documents was strongly affected by restrictions of technology type, and thus side-by-side comparison of these documents with others that focused on Al generally was unlikely to be maximally useful. On the other hand, we included principles documents that are sector-specific, focusing for example on the impacts of Al on the workforce or criminal justice, because they were typically similar in scope to the general documents.

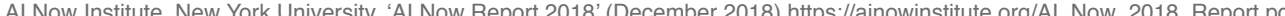
${ }^{13}$ See generally, Access Now (n 9 ).

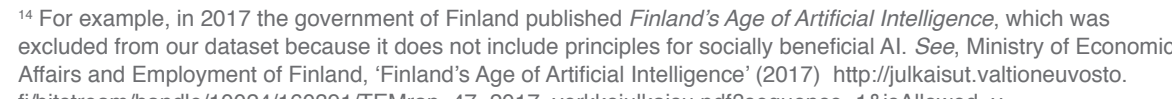

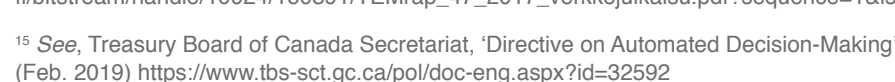


Due to the flexibility of our definition, there remains a broad range among the documents we did include, from high-level and abstract statements of values, to more narrowly focused technical and policy recommendations. While we questioned whether this should cause us to narrow our focus still further, because the ultimate goal of this project is to provide a description of the current state of the field, we decided to retain the ful range of principle types we observed in the dataset, and encourage others to dive

deeper into particular categories according to their interests.

\section{Document Search Methodology}

end the associated data visualization are based was assembled using a purposive sampling method. Because a key aim of the project from the start was to create a data visualization that would facilitate side by side comparison of individual documents, it was important that the dataset be manageably sized, and also that it represent a diversity of viewpoints in terms of stakeholder, content, geography, date, and more. We also wanted to ensure that widely influential documents were well represented. For this reason, we determined that purposive sampling with the goal of maximum variation among influential documents in this very much emergent field was the most appropriate strategy.

Our research process included a wide range of tools and search terms. To identify eligible documents, our team used a variety of search engines, citations from works in the field, and expertise and personal recommendations from others in the Berkman Klein Center community. Because the principles documents are not academic publications, we did not make extensive use of academic databases. General search terms included a " combination of "Al" or "artificial intelligence" and "principles" "recommendations," "strategy," "guideline," and "declaration" amongst others. We also used knowledge from "our community to generate the names of organizations - companies, governments, civil society actors, etc. - might have principles documents, and then we then searched those organizations' websites and publications.

In order to ensure that each document earned its valuable real estate in our

visualization, we required that it represent the views of an organization or institution; be authored by relatively senior staff; and, in cases of multistakeholder documents, contain a breadth of involved experts. It is worth noting that some government documents are expert reports commissioned by governments rather than the work of civil servants, but all documents included in this category were officially published.

Our search methodology has some limitations. Due to the language limitations of our team, our dataset only contains documents available in English, Chinese, French,
German, and Spanish. While we strove for broad geographical representation, we were unable to locate any documents from the continent of Africa, although we understand that certain African states may be currently engaged in producing Al national strategy documents which may include some form of principles. Furthermore, we recognize the possibility of network bias - because these principles documents are often shared through newsletters or mailing lists, we discovered some documents through word of mouth from those in our network. That being said, we do not purport to have a complete dataset, an admirable task which has been taken up by others. ${ }^{17}$ Rather we have put

together a selection of prominent principles documents from an array of actors.

\section{Principle and Theme Selection Methodology}

As principles documents were identified, they were reviewed in team meetings for conformity with our criteria. Those that met the criteria were assigned to an individual team member for hand coding. That team member identified the relevant pages of the document, in the case that the principles formed a sub-section of a longer document, and hand-coded all text in that section. In the initial phase, team members were actively generating the principle codes that form the basis of our database. They used the titte of the principle in the document, or if no title was given or the title did not thoroughly capte the principe the priciples content pap under that principle rather than entering a duplicate.

When the team had collected and coded approximately twenty documents, we collated the list of principles, merging close equivalents, to form a final list of forty-seven principles. We then clustered the principles, identifying ones that were closely related both in terms of their dictionary meanings (e.g. fairness and non-discrimination) as well as ones that were closely linked in the principles documents hemselves (e.g. transparency and explainability). We arrived at eight total themes, each with between three and ten principles under it:

- Privacy (8 principles)

- Accountability (10 principles)

- Safety and security (4 principles)

- Transparency and explainability (8 principles)

- Fairness and non-discrimination (6 principles)

Human control of technology (3 principles)

- Professional responsibility (5 principles)

Promotion of human values (3 principles) 
We also collected data on references to human rights in each document, whether to human rights as a general concept or to specific legal instruments such as the UDHR or the ICCPR. While this data is structured similarly to the principles and themes, with individual references coded under the heading of International Human Rights, because the references appear in different contexts in different documents and we do not capture that in our coding, we do not regard it as a theme in the same way that the foregoing concepts are. See Section 4 for our observations of how the documents in our dataset engage with human rights.

Both the selection of principles that would be included in the dataset and the collation of those principles into themes were subjective, though strongly informed by content of the early documents in our dataset and the researchers' immersion in them. This has led to some frustrations about their content. For example, when we released the draft data visualization for feedback, we were frequently asked why sustainability and environmental responsibility did not appear more prominently. While the authors ane sensitive to the significant impact $\mathrm{Al}$ is having, and will have, on the environment $18 \mathrm{we}$ did not find a concentration of related concepts in this area that would rise to the "we a theme and as such have included the principle "environmel the Accountability theme as well as discussion ofl's environm "Ieveraged to befit sociely" principe under he Promiton of Human Valses the may be that as the conversation around Al principles contin or to evolve, sustaine. becomes a more prominent theme.

Following the establishment of the basic structure of principles and themes, we were conservative in the changes we made because work on the data visualization, which depended on their consistency, was already underway. We did refine the language of the principles in the dataset, for example from "Right to Appeal" to "Ability to Appeal," when many of the documents that referenced an appeal mechanism did not articulate it as a user's right. We also moved a small number of principles from one theme to another when further analysis of their contents demanded; the most prominent example of this is that "Predictability," which was included under the Accountability theme at the time our draft visualization was released in summer 2019, has been moved to the Safety and Security theme.

Because the production of the data visualization required us to minimize the number of these changes, and because our early document collection (on which the principles and themes were originally based) was biased toward documents from the U.S. and E.U., there are a small number of principles from documents - predominantly non-Western documents - that do not fit comfortably into our dataset For example the Japanese competition law with a caution that "[e]ven if resources related to Al are concentrated in a specific country, we must not have a society where unfair data collection and infringement of sovereignty are performed under that country's dominant position." 19 We have coded this language within the "access to technology" principle under the Promotion of Human Values theme, but it does push at the edges of our definition of tha principle, and is imperfectly captured by it. Had this document been part of our initial sample, its contents might have resulted in our adding to or changing the forty-seven principles we ultimately settled on.

We therefore want to remind our readers that this is a fundamentally partial and subjective approach. We view the principles and themes we have advanced herein as simply one heuristic through which to approach Al principles documents and understand their content Other people could have made, and will make in future, other choices about which principles to include and how to group them. 


\title{
PRINCIPLED ARTIFICIAL INTELLIGENCE
}

A Map of Ethical and Rights-Based Approaches to Principles for Al

DOCUMENT TIMELINE

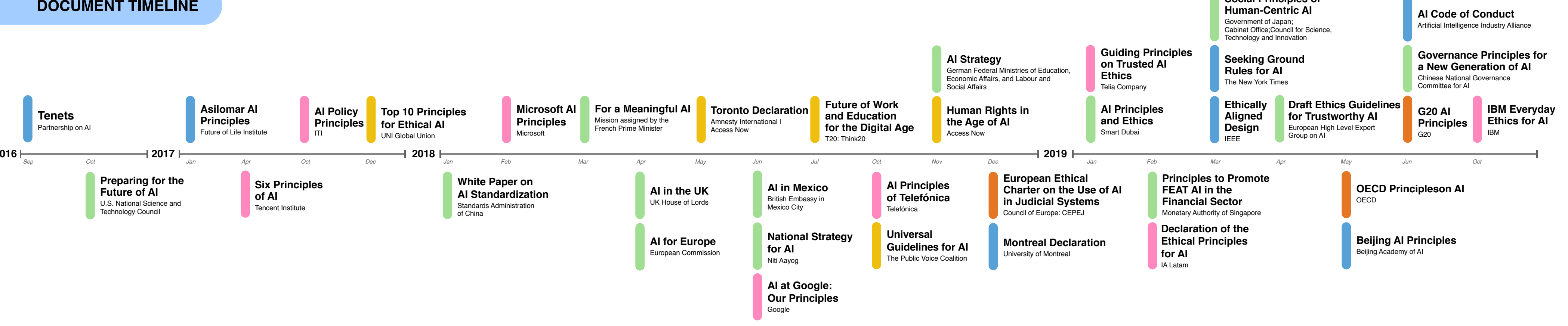

\author{
Civil Society \\ Government \\ Inter-governmental Organization \\ Multistakeholder \\ Private Sector
}




\section{Themes among} Al Principles

This section describes in detail our findings with respect to the eight themes, as well as the principles they contain:

- Privacy

- Accountability

- Safety and security

- Transparency and explainability

- Fairness and non-discrimination

- Human control of technology

- Professional responsibility

- Promotion of human values

Coverage of each theme offers a view into its core features, relevance, and connection to other themes and principles. Further, we offer a detailed look at the principles under each theme, including insights generated by comparing how the principles were variously framed by the documents in our dataset.

\subsection{Privacy}

Privacy - enshrined in international human rights law and strengthened by a robust web of national and regional data protection laws and jurisprudence - is significantly impacted by Al technology. Fueled by vast amounts of data, $\mathrm{Al}$ is used in surveillance, advertising healthcare decision-making and a multitude of other sensitive contexts. Privacy is not only implicated in prominent implementations of $A$, but also behind the scenes, in the development and training of these systems privacy is a prominent documents in our dataset, consisting of eight documents " our dataset, consisting of eight of data," "ability to restrict data processing."

"right to rectification," "right to erasure,"

"right to rectification," "right to erasure, protection laws," and "privacy (other/general).

The General Data Protection Regulation of the European Union (GDPR) has been enormously influential in establishing safeguards for personal data protection in the current technological environment, and many of the documents in our dataset were clearly drafted with provisions of the GDPR in mind. We also see strong connections between principles under the Privacy theme and the themes of Fairness and Non-Discrimination, Safety and Security, and Professional Responsibility.

PRINCIPLES UNDER THIS THEME

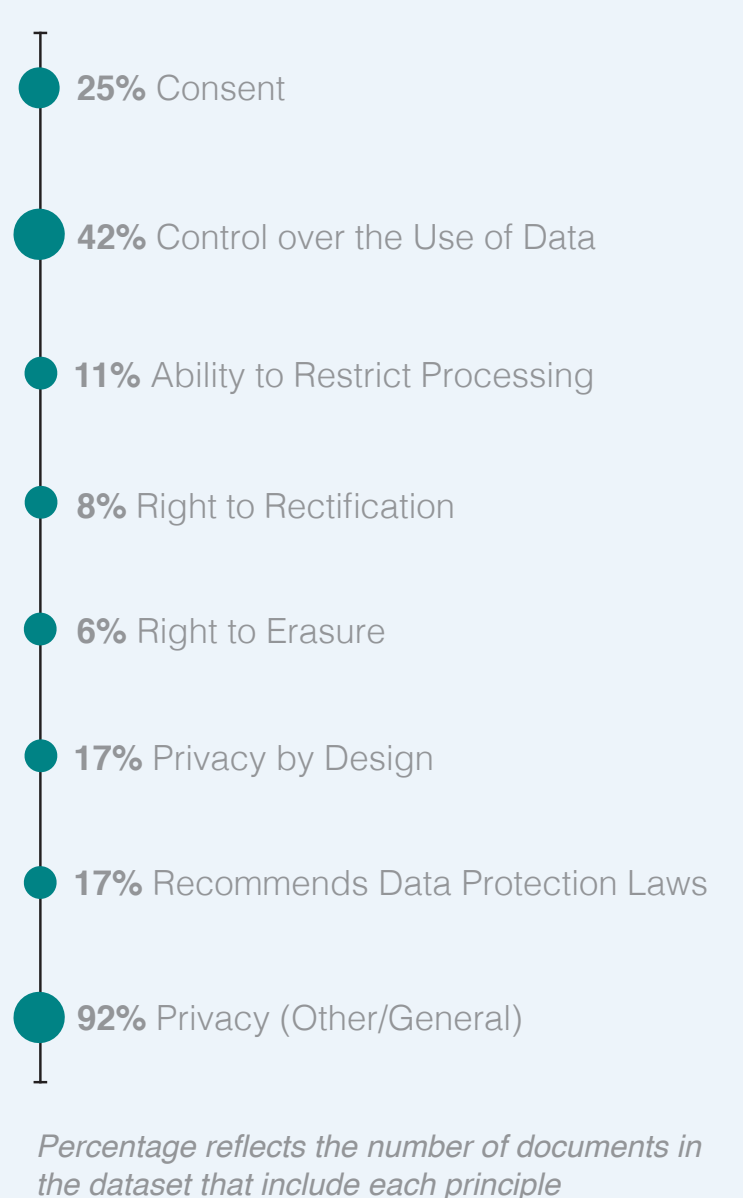

Percentage reflects the number of documents in 


\section{Consen}

Broadly, "consent" principles reference the notion that a person's data should not be used without their knowledge and permission. Informed consent is a closely related but more robust principle - derived from the medical field - which equires individuals be informed of risks, benefits, and alternatives. Arguably, some formulation of "consent" is a necessary component of a full realization of other principles under the Privacy theme, including "ability to restrict processing," "right to rectification," "right to erasure," and "control over the use of data."

Documents vary with respect to the depth of their description of consent, breaking into two basic

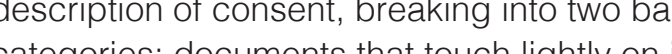
cernops outlining a simple notice-andy on it, perhaps oulling a egine, cow dont specilically or even expand upon it. ${ }^{20}$ A few documents, such as Google's Al principles and IA Latam's principles, do not go beyond defining consent as permission, but as a gener matter, informed consent or otherwise nonperfunctory processes to obtain consent feature prominently in the corpus.

The boldest departures from the standard noticeand-consent model can be found in the Chinese White Paper on Al Standardization and Indian Al

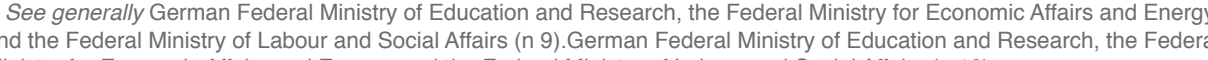
Mnistry for Econonis

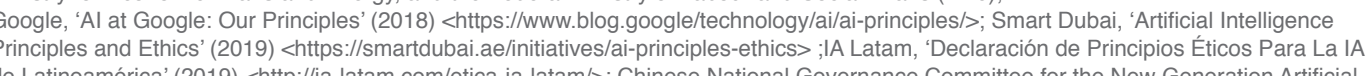

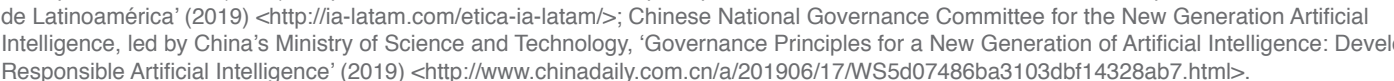

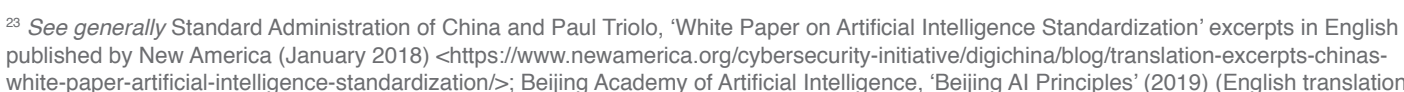

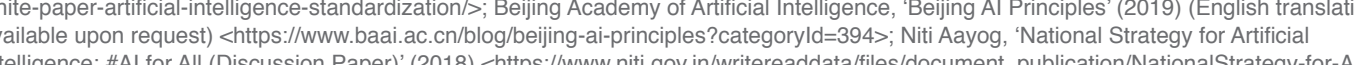

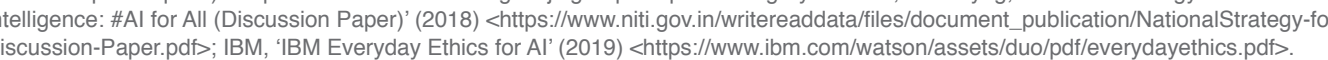

"Standard Administration of China and Triolo (n 24) Principle 3.3.3.

${ }^{25}$ Niti Aayog (n 24) p. 88. how their data is used and for what purpose should be qualified in various ways. Microso commits to giving consumers "appropriate controls so they can choose how their data is used"26 and IEEE notes that where minors an those with diminished capacity are concerned, recourse to guardianship arrangements may be required. ${ }^{27}$ However, several documents do contain articulations of the control principle that are more absolute. The IBM AI principles state that "Users should a/ways maintain control over what data is being used and in what context." ${ }^{28}$ On the other hand, the German Al strategy clearly states the importance of balancing and repeatedly articulates people's control over their personal data as a qualified "right." The German document suggests the use of "pseudonymized and anonymized data" as potential tools to "help strike the right balance between protecting people's ight to control the the righ ba

There is some differentiation between the documents on the question of where control ought to reside. Some dedicate it to individuals, which is typical of current systems for data control. On the other hand, some documents would locate control in specially dedicated tools, institutions, or systems. For example, the European Commission's High-Level Expert Group describes the creation of "data protocols and "duly qualified personnel" who would govern access to data. ${ }^{30}$ EEE proposes the implementation of a technology that would allow individuals to assign "an online agent" to help make "case-by-case authorization decisions as to who can process what persona data for what purpose." This technology might even be a dynamically learning Al itself -

evaluating data use requests by third parties in an "autonomous and intelligent" manner. ${ }^{31}$ Lastly, Al in the UK advocates "data trusts" that would allow individuals to "make their views heard and shape ... decisions" through some combination of consultative procedures, "personal data representatives," or other mechanisms. ${ }^{32}$

\section{Ability to Restrict Processing}

The "ability to restrict processing" refers to the power of data subjects to have their data restricted from use in connection with $\mathrm{Al}$ technology. Some documents coded for this principle articulate this power as a legally enforceable right, while others stop short of doing so. For example, whe Access Now report would "give people the ability to request that an entity stop using or limit the use of personal information." "'33 Notably, Article 18 of the GDPR has legally codified this right with respect to data processing more generally, but documents within our dataset diverge in some respects from the GDPR definition.

The extent to which data subjects should be able to restrict the processing of their data is clearly in contention. For instance, the Montreal Declaration asserts that people have a "right to digital

Microsoft, 'Al Principles' (2018) p. 68 <https://www.microsoft.com/en-us

e on Ethics of Autonomous and Intelligent Systems (n 5 ) p.2

${ }_{28}^{28}$ IBM (n 24) p. 44

2"German Federal Ministrty of Education and Research, the Federal Ministry for Economic Aftairs and

European Commission's High-Level Expert Group on Atrificial Intelligence ( $(n)$ p. 17.

UK House of Lords, Select Committee on Artificial Intelligence (n 8) p. 126

${ }_{33}$ Access Now (n 10) p. 3 
on Al-driven systems to "explicitly offer the option to disconnect at regular intervals, without encouraging people to stay connected, ${ }^{34}$ and an earlier draft of the European High Level Expert Group guidelines placed a positive obligation on government data controllers to "systematically" offer an "express opt-out" to citizens. ${ }^{35}$ However, the final version of the HLEG guidelines was far less expansive, narrowing the right to opt-out to "citizen scoring" technologies in "circumstances where ... necessary to ensure compliance with fundamental rights." ${ }^{36}$

\section{Right to Rectification}

The "right to rectification" refers to the right of data subjects to amend or modify information held by a data controller if it is incorrect or incomplete. As elsewhere where the word "right" is contained in the titte we only coded documents under this principle where they explicitly articulated it as a ight or obligation. High-quality data cod tibus a to safety, fairness, and aualy data contributes so this princips is cloly reated to the f Fainess and Non-Discrimination and Safy

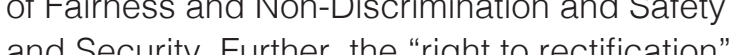
is closely related to the "ability to restrict processing," insofar as they are both part of a continuum of potential responses a data subject might have in response to incorrect or incomplete information.

Rectification is not a frequently invoked principle appearing in only three documents within our dataset. The Access Now report recommends right to rectification closely modeled after that contained in Article 16 of the GDPR. The Singapore Monetary Authority's Al principles place a positive obligation on firms to provide data subjects with "online data management tools" that enable individuals to review, update, and edit information for accuracy ${ }^{37}$ Finally, the T20 report on the future of work and education addresses this principle from a sector-specific viewpoint, describing a right held by employees and job applicants to "have access to the data held on them in the workplace and/or have means to ensure that the data is accurate and can be rectified, blocked, or erased if it is inaccurate."

\section{Right to Erasure}

The "right to erasure" refers to an enforceable right of data subjects to the removal of their personal data. Article 17 of the GDPR also contains a right to erasure, which allows data subjects to request the removal of personal data under a defined set of circumstances, and provides that the request should be evaluated by balancing rights and interests of the data holder, general public, or other relevant parties. The Access Now repo models its recommendation off of Article 17 stating:

T]he Right to Erasure provides a pathway for deletion of a person's personal data held by a third party entity when it is no longer necessary, the information has been misused, or the relationship between the user and the entity is terminated. ${ }^{39}$

However, other documents in the dataset advance a notion of the right to erasure distinct from the GDPR. Both the Chinese Al governance principles and the Beijing Al Principles include a call for "revocation mechanisms." ${ }^{40}$ In contrast to the Access Now articulation, the Beijing Al Principles provide for access to revocation mechanisms in "unexpected circumstances." "41 Further, the Beiijing document conditions that the data and service revocation mechanism must be "reasonable" and that practices should be in place to ensure the protection of users' rights and interests. The version of the erasure principle in the T20 report on the future of work and education is even more nerrowly tailored, and articultes a right to more (or data on past, pres her violates the right to privacy. ${ }^{42}$

\section{Privacy by Design}

"Privacy by design," also known as data protectio by design, is an obligation on Al developers and operators to integrate considerations of data privacy into the construction of an Al system and the overall lifecycle of the data. Privacy by design is codified in Article 25 of the GDPR, which stipulates data controllers must "implement appropriate technical and organisational measures..." during the design and implementation stage of data processing "to protect the rights of data subjects." ${ }^{43}$ Perhaps in recognition of these recent regulatory advances BM simply commits to adhering to national and Anternational rights laws during the design of an Al's data access permissions. ${ }^{4}$

In the private sector, privacy by design is egarded as an industry best practice, and it is under these terms that Google and Telefónica consider the principle. Google's Al principles document does not use the phrase "privacy by design" but it does commit the company to incorporate Google's privacy principles into the development and use of Al technologies and to "encourage architectures with privacy safeguards." ${ }^{45}$ Telefónica also points to its privacy policy and methodologies, stating: "In order to ensure compliance with our Privacy Policy we use Privacy by Design methodology. When building Al systems, as with other systems, we follow Telforica's Securty by Desigh we follow Telefonica's Security by Design to "ethics by does a step further, committing to "ehics by design," a phrase that can be best understood as the integration of principles into whe is what is legally required, and connects strongly with the "responsible design" principle under the Professional Responsibility theme.

\section{Recommends Data Protection Laws}

The "recommends data protection laws" principle, simply put, is that new government regulation is a necessary component of protecting privacy in the face of Al technologies. Documents produced on behalf of the governments of France, Germany,
3. University of Montreal, 'Montreal Declaration for a Responsible Development of Artificial Intelligence' (2018) p.

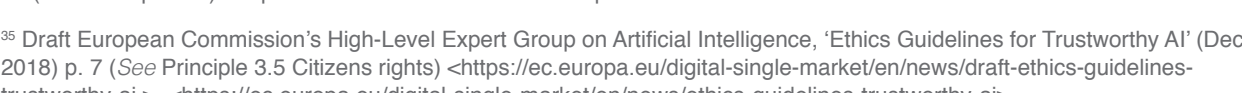

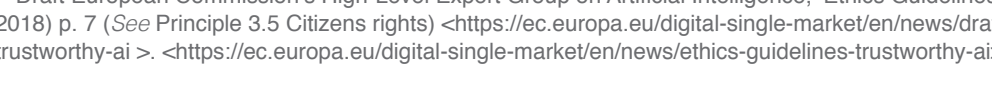

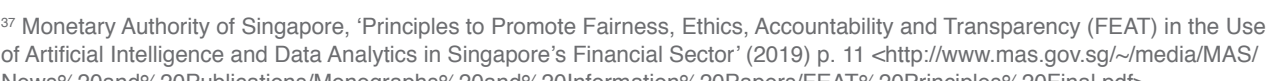

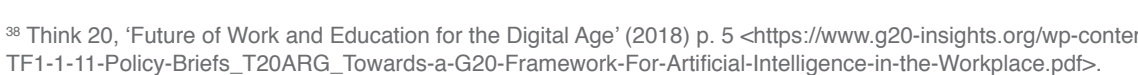

Access Now (n 10) p. 31 Bejijing Academy of Artificial Intelligence (n 23) (See Principle 2.2, English translation available upon request)

"2 Think 20 (n 39) p. 5

${ }^{2}$ GDPR Art. 25 The GDPR definition and enforcement mechanism is an instructive example of privacy by design and Article 25
even specifies techniques, such as pseudonymization and data minimization, tor data processors to implement.

I4 IBM (n 24) P. 44.

${ }_{45}^{4}$ Google (n 23) (See Principle 5.) 
Mexico, and India each call for the development of new data privacy and data protection frameworks. These calls for regulation tend to be aspirational in their framing, with a common acknowledgement neatly articulated in the Access Now report - th data protection legislation can anticipate and mitigate many of the human rights risks posed by Al. ${ }^{\prime 46}$ Other documents add that the "diverse and fast changing nature of the technology" requires a "continually updated" privacy protection regime. ${ }^{47}$ The importance of agile regulatory frameworks is reiterated in the Al in Mexico Institute for Transparency, Access to Information and Protection of Personal Data "to keep pace with innovation." 48

The European documents that address this principle do so in the context of an already highly prective rego. The German strategy document angests hat there exists a gap in that regime, 'that would proct enploy' Das' Protection Act that would protect employees data in the age of Al." "This narrow approach contrasts with the French strategy document, which critiques current legislation, and the rights framework more fundamentally, as too focused on "the protection of the individual" to adequately contend with the potential collective harms machine learning and Al systems can perpetuate. The French document

\section{Access Now (n 10) 30}

"av Niti Aayog (n 24) p. 87.

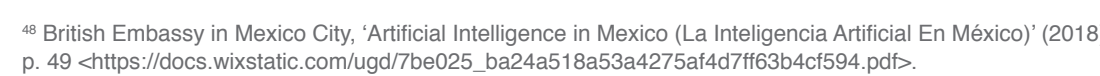

49 GGerman Federal Ministry of Education and Research, the Federal Ministry for Economic Aftairs and
Energy, and the Federal Ministry of Labour and Social Affairs (n 10) p. 28.

"Mission assigned by the French Prime Minister (n 8) 114

"Niti Aayog (n 24) p. 87.

Nin

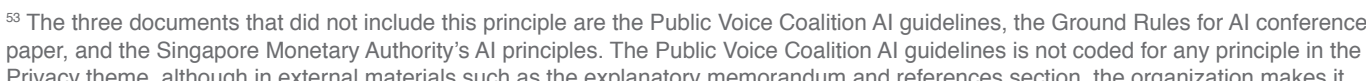

Privacy theme, although in external materials such as the explanatory memorandum and referencees section, the organization makes

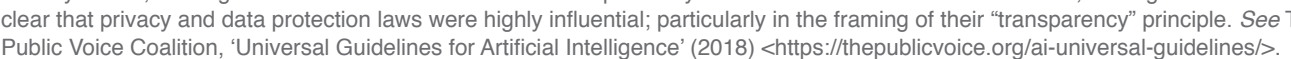

Privacy is frequently called out as the prime example of the relevance of a rights framework Al technology. The OECD and G20 Al principles call for "respect [for] the rule of law, human righ and democratic values," including respect for privacy. ${ }^{54}$ The Toronto Declaration, which takes human rights as an overall framework for its approach to Al governance, also highlights the importance of privacy, stating that "States must adhere to relevant national and international laws and regulations that codify and implement human rights obligations protecting against discrimination and other related rights harms, for example dat protection and privacy laws." ${ }^{55}$ Finally, in the private sector, where Al principles most commonly take the form of internal company commitments, Telia Company engages to examine the "honts, The manage human rights risks and opportunities, including Microsoft, Telefónica, IA Latam, and IBM describe ricosot, Telefonica, IA Latam, and IBM aescribe respect or privacy as a legal obligation

Outside of compliance, we found a wealth of other grounds for the primacy of privacy. The German as not only necessary from a legal and ethica standpoint but as "a competitive advantage internationally." ${ }^{57}$ Google, and ITI describe respec of user privacy as a corporate responsibility owed to users and a business imperative. ${ }^{58}$ The U.S. Science and Technology Council report balances consumer privacy against the value of "rich sets of data." ${ }^{59}$ Other non-legal justifications included cybersecurity benefits, ${ }^{60}$ alignment with public opinion, ${ }^{61}$ and the author institution's preexisting public commitment to a set of privacy principles. 


\subsection{Accountability}

On its face, the term "artificial intelligence suggests an equivalence with human intelligence. Depending on who you ask, the age of autonomous Als is either upon us or uncertain centuries in the future, but concerns about who will be accountable for decisions that are no longer made by humans - as well as the potentially enormous scale of this technology's impacts on the social and natural world - likely lie behind the prevalence of the Accountability theme in our dataset ${ }^{63}$ Account all documents that we aset.. mention at principle: "recommends adoption of new principle: "recoms "verifiablity and replicabiliy." regulations, "verifabilly and replicability, " "mpact assessments," "envionmental responsibility," "evalualion and auditing requirements, " "creation of a monitoring body, "ability to appeal," "remedy for responsibility," and "accountability per se.
PRINCIPLES UNDER

$$
\text { THIS THEME }
$$

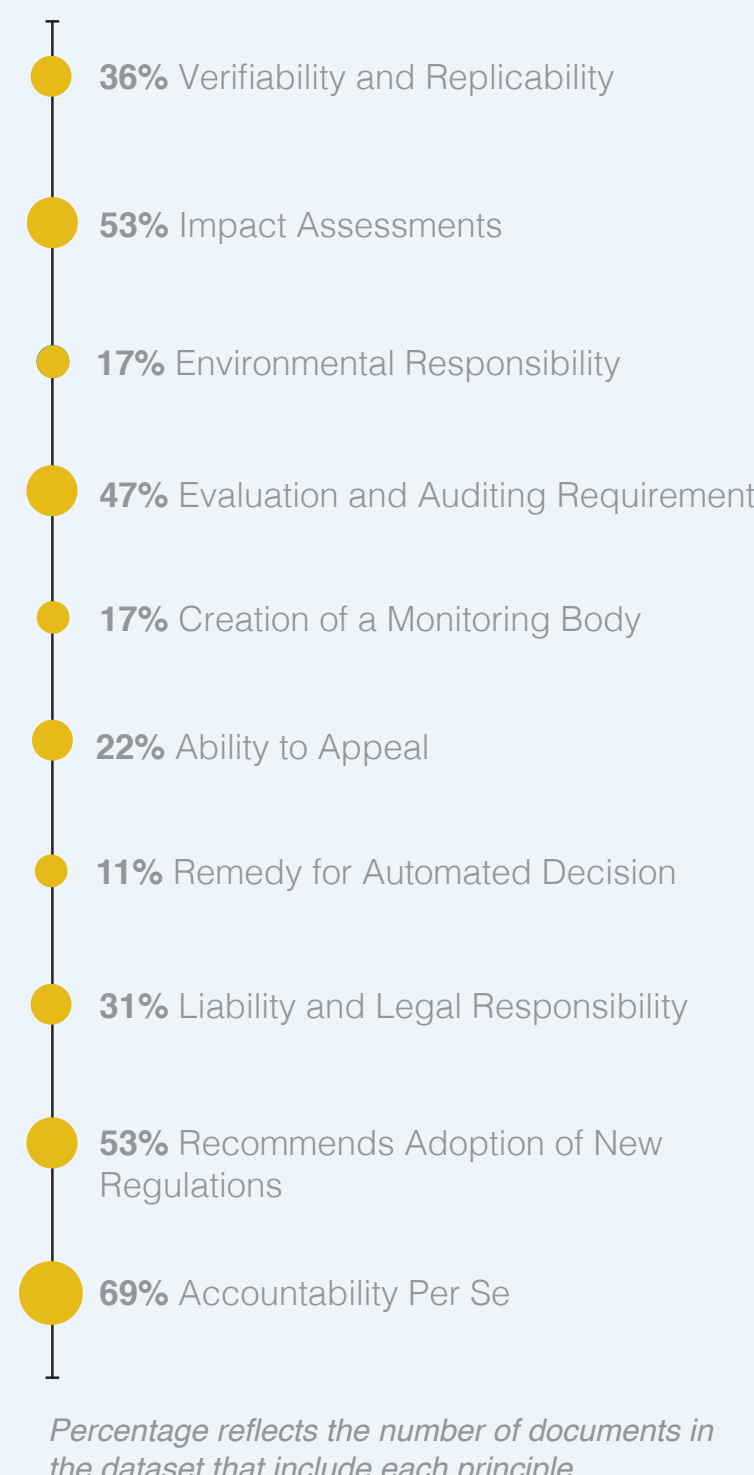

the dataset that include each principle
The documents reflect diverse perspectives on the mechanisms through which accountability should be achieved. It's possible to map the principles within the Accountability theme across the lifecycle of an Al system, in three essential stages: design (pre-deployment), monitoring (during deployment), and redress (after harm has occurred)

\begin{tabular}{|l|l|l|}
\hline Design & Monitoring & Redress \\
\hline Verifiability and Replicability & $\begin{array}{l}\text { Evaluation and } \\
\text { Auditing Requirements }\end{array}$ & Remedy for Automated Decision \\
\hline Impact Assessment & Creation of a Monitoring Body & Liability and Legal Responsibility \\
\hline Environmental Responsibility & Ability to Appeal & $\begin{array}{l}\text { Recommends Adoption } \\
\text { of New Regulations }\end{array}$ \\
\hline
\end{tabular}

Of course, each principle may have applicability across multiple stages as well. For example, the "verifiability and replicability" and "environmental responsibility" principles listed under the design stage in the above table will also be relevant in the monitoring and redress phases, but for optimal implementation should be accounted for when the system is designed.

The Accountability theme shows strong connections to the themes of Safety and Security, Transparency and Explainability, and Human Control of Technology. ${ }^{64}$ Accountability principles are frequently mentioned together with the principle of transparent and explainable $\mathrm{Al}{ }^{65}$ often highlighting the need for accountability as a means to gain the public's trust ${ }^{66}$ in $\mathrm{Al}$ and dissipate fears. ${ }^{67}$

\section{Verifiability and Replicability}

The principle of "verifiability and replicability" provides for several closely related mechanisms to ensure Al systems are functioning as they should: an Al experiment ought to "exhibit[] the same behavior when repeated under the same conditions" 68 and provide sufficient detail about its operations that it may be validated.

6"Access Now (n 10) p. 33; Google (n 23) (See Principle 4)

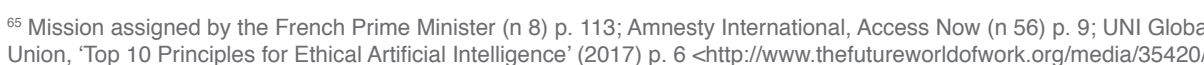

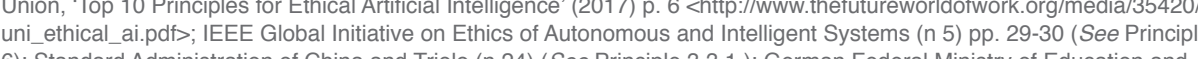

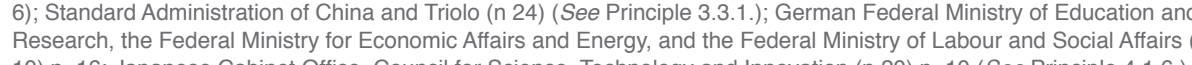

66 German Federal Ministry of Education and Research, the Federal Ministry for Economic Affairs
and Energy, and the Federal Ministry of Labour and Social Affairs (n 10) p. 16.

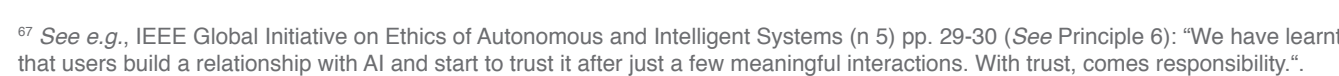
${ }^{68}$ European Commission's High.Level Expert Group on Artiticial ntalligence (n 6$)$ p. 17. 
The German AI Strategy highlights that a verifiable Al system should be able to "effectively prevent distortion, discrimination, manipulation and other forms of improper use." ${ }^{69}$ The development of verifiable Al systems may have institutional components along with technical ones. Institutionally, auditing institutions could "verify algorithmic decision-making in order to prevent improper use, discrimination and negative impacts on society"70 and "new standards, including standards for validation or certification agencies on how Al systems have been verified"71 could be developed.

\section{Impact Assessments}

The "impact assessments" principle captures both specific calls for human rights impact

assessments (HRIAs) as well as more general cals for the advance identification, prevention, and mitigation of negative impacts of Al technology. One way to measure negative impacts of $\mathrm{Al}$ ystems is to evaluate its "risks and opportunities" for human rights, ${ }^{72}$ whether through HRIAs ${ }^{7}$ or cuman rights due alligence. "Where HRIAs are called for, documents frequently also provide structure for their design: the Access Now report, for example, outlines that the assessment should nclude a consultation with relevant stakeholders "particularly any affected groups, human rights organizations, and independent human rights and $\mathrm{Al}$ experts." ${ }^{75}$ For other actors - often those ess closely grounded in the daily management of technology's human rights harms - this principle translated to calls for the assessment of "both direct and indirect harm as well as emotional, social, environmental, or other non-financial harm." "76

We observed that some documents use the terminology of potential harm ${ }^{77}$ and others call for the identification of risks 78 The emphasis, particularly among the latter category of documents, is on prevention, and impact assessments are an accountability mact bsessments are an accountability mechanism risks are "too high or impossibes mo mitige" 9) should revent an Al tecible to milgate" should prevent an Al technology from being deployed or even developed. Some documents after evaluating its "purpose and objectives, its

\section{sogerman Federal Ministry of Education and Research, the Federal Ministry for Economic Aftairs and
Energy, and the Federal Ministry of Labour and Social Affairs $n$ 10) p. 38 .}

70 German Federal Ministry of Education and Research, the Federal Ministy
Energy, and the Federal Ministry of Labour and Social Affairs $(n$ 10) p. 38.

IEEE Global Initiative on Ethics of Autonomous and Intelligent Systems (n 5) p. 28, addressing the topic within the principle of transparenor

"Telia Company (n 56) (See Principle 3

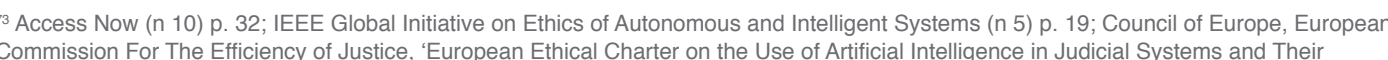

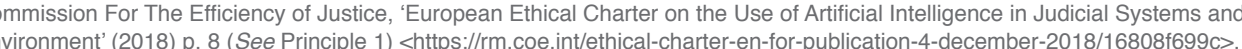

Amnesty International, Access Now (n 56) p. 12

"Access Now (n 10) p. 34

${ }^{76}$ Access Now (n 10) p. 34

Access Now (n 10) p. 34; European Commission's High-Level Expert Group on Atrificial Intelligence ( $n 6)$ p. 19.

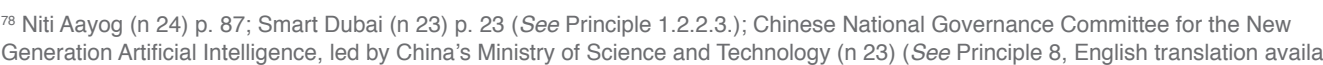

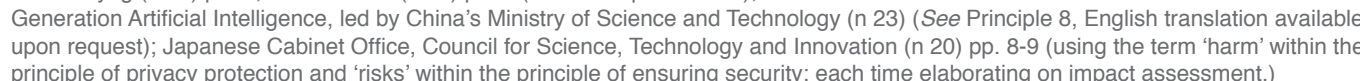

${ }_{79}$ Amnesty International, Access Now (n 56) p. 13 (See para. 48 , benefits, as well as its risks." ${ }^{80}$ In this context, it is particularly important that the Al system can be tested in a controlled environment and scaled-up as appropriate. ${ }^{81}$ The Smart Dubai Al principles document calls for the use of Al systems only if they are "backed by respected and evidencebased academic research, and Al developer

organizations." ${ }^{\prime 2}$

\section{Environmental Responsibility}

The principle of "environmental responsibility"

reflects the growing recognition that $\mathrm{Al}$, as a part of our human future, will necessarily interact with environmental concerns, and that those who build and implement Al technology must be accountable for its ecological impacts. The documents address environmental responsibility from two different angles.

Some documents capture this principle through an insistence that the environmen hould be a factor that is considered within the assessment of potential harm. IA Latam's principles, for example, stress that the impac of Al systems should not "represent a threat or our environment." ${ }^{84}$ Other documents go further, moving from a prohibition on negative amifications to prescribe that Al technologies must be designed "to protect the environment, the climate and natural resources"s5 or to "promote the sustainable development of nature and society."

\section{Evaluation and Auditing Requiremen}

The "evaluation and auditing requirement" principle articulates the importance of not only building technologies that are capable of being audited but also to use the learnings from evaluations to feed back into a system and to ensure that it is continually improved, "tuning Al models periodically to cater for changes to data and/or models over time."

A frequent focus is on the importance of human in the auditing exercise, either as an auditing authority ${ }^{89}$ or as users of Al systems who are solicited for feedback. ${ }^{90}$ The Toronto Declaration calls upon developers to submit "systems that have a significant risk of resulting in human rights abuses to independent third-party audits. The T20 report on the future of work and education focuses instead on breadh of input, highighting the need for training data and features to "be

The Public Voice Coalition (n 54) (See Principle 5

"Organisation for Economic Co-pperation and Development (n 54) p.9. 9 (See Prinipile 2.3); G20
Trade Ministers and Digital Economy Ministers (n 54) p. 13 (See Principle 2.3.)

Smart Dubai (n 23) p. 22 (See Principle 1.2.2.

European Commission's High-Level Expert Group on Artificial Intelligence (n 6) p. 19

IA Latam (n 22) (See Principle 5, English translation avaliable upon request).

Es German Federal Ministy of Education and Research, the Federal Ministry for Economic Affairs and
Energy, and the Federal Ministry of Labour and Social Aftairs $(n 10)$ p. 20 .

"Bejing Academy of Artificial Intelligence (n 42) (See Principle 1.1 English translation available upon request)

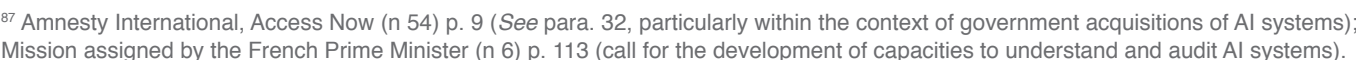

Smart Dubai (n 23) p. 23 (See Principles 1.2.2.4 and 1.2.2

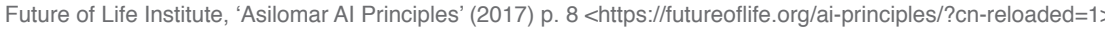

${ }^{50}$ Google (n 23) (See Principle 4.)

"Amnesty International, Access Now (n 56) p. 13 (Seee para. 47) (emphasis added) 
reviewed by many eyes to identify possible flaws and to counter the 'garbage in garbage out' trap."

Some, but not all, documents have drafted their "evaluation and auditing" principles to contain significant teeth. Some documents recommend the implementation of mechanisms that allow an eventual termination of use. Such a termination is recommended, in particular, if the Al systems "would violate international conventions or human rights." "93 The Access Now report suggests the development of "a failsafe to terminate acquisition deployment, or any continued use if at any point an identified human rights violation is too high or nable to be mitigated"

\section{Creation of a Monitoring Body}

\section{The principle of "creation of a monitoring body"}

reflects a repeated recognition that some new

organization or structure may be required to create

and oversee standards and best practices in the

context or A. Visions for how these bodies may

undertake vary.

The Ethically Aligned Design document situates the need for this new body in its pursuit to

ensure that Al systems do "not infringe upon

human rights, freedoms, dignity, and privacy."

${ }^{20}$ Think 20 (n 39) p. 6.

"aA Access Now (n 10) p. 33.

"IEEE Global Initiative on Ethics of Autonomous and Intelligent Systems (n 5) p. 19 (See Principle

Amnesty International, Access Now (n 55) p. 10

"German Federal Ministry of Education and Research, the Federal Ministry for Economic Aftairs and
Energy, and the Federal Ministry of Labour and Social Affairs (n 9) p. 26.

"se UNI Global Union (n 66) p. 7: Google (n 23) (See Principle 4)

Think 20 (n 38 ) p. 8.

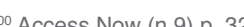

Microsoft's Al principles suggest the creation of "internal review boards" - internal, we presume to the company, but not to the teams that are building the technology. The Toronto Declaration stresses that any monitoring body should be independent and might include "judicial authorities when necessary." "96 The German Al strategy outlines the creation of a national Al observatory, which could also be tasked to monitor that Al systems are designed socially compatible and to evelop auditing standards. ${ }^{97}$

\section{Ability to Appea}

The principle of an "ability to appeal" concerns the possibility that an individual who is the subject of a decision made by an Al could challenge that decision. The ability to appeal connects with the theme of Human Control of Technology in that it's often mentioned in connection with the principles of "right to human review of an automated

"cision." ${ }^{98}$ Some documents in fact collapse the in the Access Now report calls the human accountability." ${ }^{100}$

In some individual documents, this principle is parsed more neatly, as for example in the Access Now report which explains that there should be both an ability to challenge the use of an Al system and an ability to appeal a decision that has been "informed or wholly made by an Al system." 101 T ability to appeal the use of or recommendation made by an Al system could be realized in form of a judicial review. ${ }^{102}$ Further, some documents limit the ability to appeal only to "significant automated decisions." ${ }^{103}$

A subset of documents recognize as part of this principle the importance of making Al subjects aware of existing procedures to vindicate their rights ${ }^{104}$ or to broaden the accessibility of channels for the exercise of subjects' rights. ${ }^{105}$ In order to enable $\mathrm{Al}$ subjects to challenge the outcome of $\mathrm{Al}$ systems, the OECD and G20 Al principles sugges that the outcome of the system must be "based on lain and easy-to-understand information on the actors, and the logic that served as the basis for

\section{Remedy for Automated Decisio}

\section{The principle of "remedy for automated}

decision" is fundamentally a recognition that as Al technology is deployed in increasingly critical contexts, its decisions will have real consequences, and that remedies should be avaliable just as they are for the consequences of human actions. The principle of remedy is intimately connected to the ability to appeal,

Access Now (n 55) p. 14

"A

Organisation for Economic Co-operation and Development (n 54) p. 8 (See Principle 1.3); G20

Amnesty International, Access Now (n 55) p. 15 (See Principle 53.

(S) Principle 56.

'A Access Now (n 10) p. 35 (See para. 3 . since where appeal allows for the rectificatio of the decision itself, remedy rectifies its consequences. ${ }^{107}$

There is a bifurcation in many of the documents mechanisms that are appropriate for state use of Al versus those that companies should implement for private use. For example, the Toronto Declaration has separate principles for company and state action, providing that companies may "for example, creat[e] clear, independent, visible processes for redress ollowing adverse individual or societal effects, and designat[e] roles in the entity responsible for the timely remedy of such issues" 108 whereas states should provide "reparation that where appropriate, can involve compensation, sanctions against those responsible, and guarantees of non-repetition. This may be possible using existing aws and regulations or may require developing new ones." "109 Other documents suggest further important delmealions of responsibilles, including

\section{Liability and Legal Responsibility}

The principle of "liability and legal responsibility" refers to the concept that it is necessary to ensure that the individuals or entities at fault for harm 
caused by an Al system can be held accountable. While other forms of automation and algorithmic decision making have existed for some time, emerging Al technologies can place further distance between the result of an action and the actor who caused it, raising questions about who should be held liable and under what circumstances. These principles call for reliable resolutions to those questions.

Many documents point out that existing systems may be sufficient to guarantee legal responsibility for Al harms, with actors including Microsoft and the Indian Al strategy looking to tort law and specifically negligence as a sufficient solution. Others, such as the Chinese Al Industry Code of Conduct, assert that there is additionat obe done to "clions d and service the responsible parties when harm occurs "11

There exists some reluctance to hold developers liable for the consequences of Al's deployment. The Chinese White Paper on Al Standardization distinguishes in its principle of liability between liability at the level of development and at the level of deployment, recommending transparency as the most appropriate accountability mechanism at the development level and suggesting the

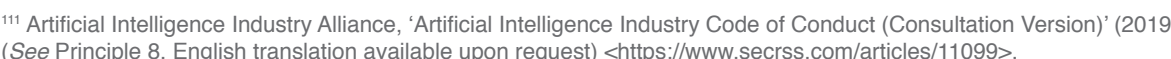

(Stanch

Is University of Montreal (n 35) p. 16 (See Principle 9.5.

(2018)

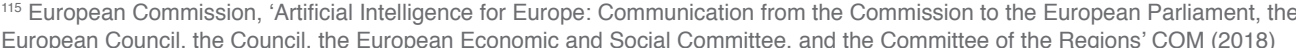

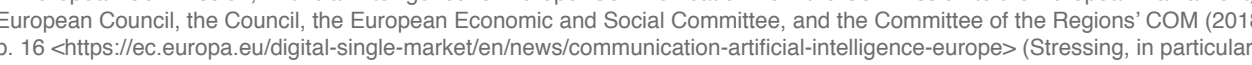

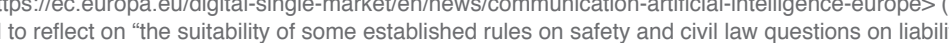

UK House of Lords, Select Commititee on Artificial Intelligence (n 8) p. 135 (See para. 56 )

"Information Technology Industry Council (n 8) p. 4.

18 Access Now (n 9) p. 32
Among statements of this principle, we see a variety of justifications for future regulation, som of which are recognizable from other themes in our data: the regulation should ensure that the development and use of Al is safe and beneficia to society; 119 implement oversight mechanisms "in contexts that present risk of discriminatory or other rights-harming outcomes;"'120 and identify the right balance between innovation and privacy rights.

There is also a common emphasis on the need for careful balancing in crafting regulation. The trade industry group ITI cautions that new regulations might "inadvertently or unnecessarily impede the responsible development and use of Al."12 On the other hand, the OECD Al principles and 20 Al principles state that appropriate policy and regulatory frameworks can "encourage and regulatory frameworks can "encourage Many documents recognize that new laws and regulactions are appropriate thawnakers use

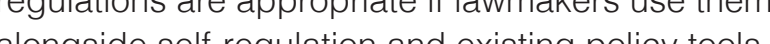
The Al for Europe docum axt The Al for Europe document states that "selfregulation can provide a first set of benchmarks" but that the European Commission should "monitor legal frameworks." 124 The Standards Administration of China suggested that new regulations might be based on "universal regulatory principles" 125 th would be formulated at an international leve.

\section{Accountability Per Se}

Like many of our themes, the Accountability theme contains an "accountability" principle, but in this specific case, only to those documents that explicitly use the word "accountability" or "accountable" (25 of the 36 documents) were coded under this principle. Because principles documents are frequently challenged as toothless or unenforceable, we were interested to see how documents grappled with this term specifically. In this context documents converge on a call for developing "accountability frameworks" 126 that define the responsibility of different entities "at each stage in research and development, design, each stage in research and development, design

Notably, a few documents emphasize that the tystems cannot lie with the technology itself, but should be apportioned between those who design, develo and deploy [it]." 28 Some documents propose specific entities that should be held accountable

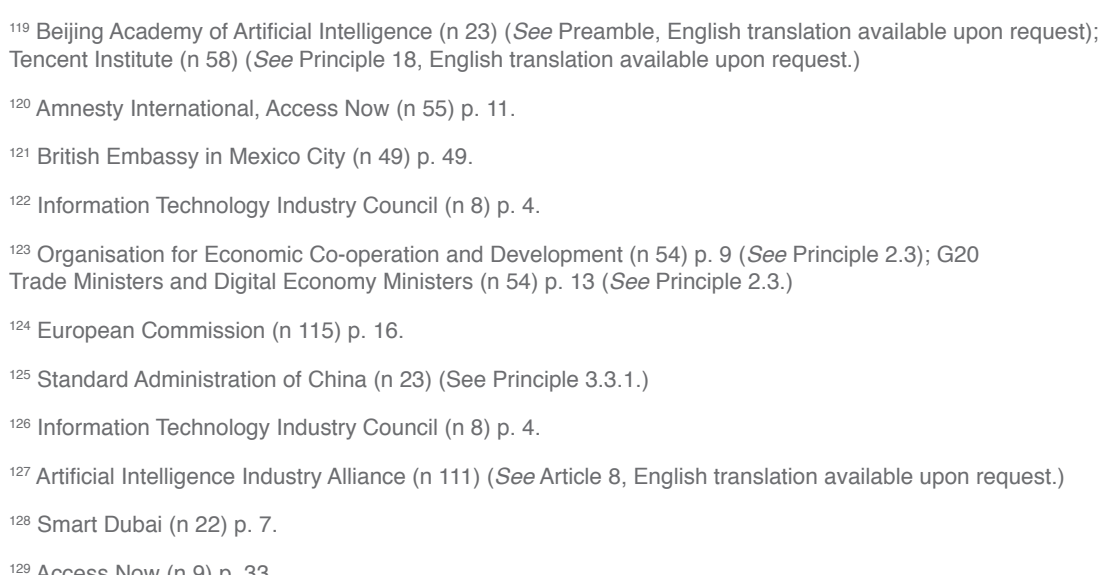


companies and their business partners, ${ }^{130}$

researchers, developers and users. The OECD

Al principles and G20 Al principles suggest that

accountability should adapt to the context in whic

the technology is used.

\subsection{Safety and Security}

Given early examples of Al systems' missteps ${ }^{133}$ and the scale of harm they may cause, concern about the safety and security of Al systems were unsurprisingly a significant theme among principles in the documents we coded. ${ }^{134}$ There appears to be a broad consensus across different actor types on the centrality of Safety and Security with about three-quarters of the documents addressing principles within this theme. There are four principles under it: "safety, "security," "security by design," and "predictability."

It is worth distinguishing, up front, the related concepts of safety and security. The principle of safety generally refers to proper internal functioning of an Al system and the avoidance of unintended harms. By contrast, security addresses external threats to an Al system. However, documents in our dataset often mention the two principles together, and indeed they are closely intertwined. This observation becomes particularly evident documents use the related term "reliability", 135 "a

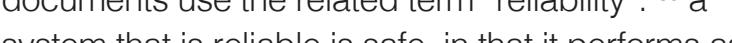
system that is relable is safe, in that il performs as intended, and also secure, in that it is not vulnerable to being compromised by unauthorized third parties.

There are connections between this theme and

PRINCIPLES UNDER THIS THEME

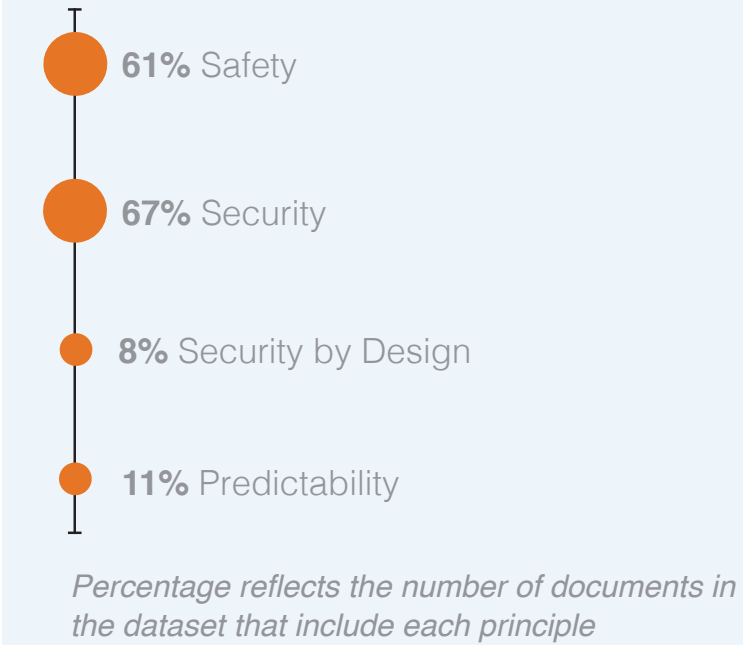

the Accountability, Professional Responsibility, and Human Control of Technology themes. In many ways, principles under these other themes can be seen, at least partially, as implementation mechanisms for the goals articulated under Safety and Security 
Accountability measures are key guarantors of Al safety, including verifiability ${ }^{136}$ and the need to monitor the operation of Al systems after thei deployment. ${ }^{137}$ Individuals and organizations behind Al technology have a key role in ensuring it is designed and used in ways that are safe an secure. Safety is thus frequently mentioned in connection with the need to ensure controllability by humans. ${ }^{138}$

\section{Safety}

The principle of "safety" requires that an Al system be reliable and that "the system will do what it is supposed to do without harming living beings or [its] environment." 139 Articulations of this principle focus both on safety measures to be taken both before Al systems are deployed 140 taken both "throre measures during derational ifetme." Safety systems are "bult and tested to prever misuse."142 "Buill and tested to prevent possible "risuse. " "Building systems safely means avoiding "nsks or ham mo by assessing safely risks Testing procedures should not only apply to likely scenarios, but also establish that a system "responds safely to unanticipated situations and does not evolve in unexpected ways." 140

Testing and monitoring of Al systems should continue after deployment according to a few articulations of the "safety" principle. This is particularly relevant where the document focuses on machine learning technology, which is likely to evolve following implementation as it continues to receive input of new information. Developers of Al systems cannot always "accurately predict the risks"147 associated with such systems ex ante. There are also safety risks associated with Al systems being implemented in ways that the creators did not anticipate, but one document suggests that designing Al the could be cument fere called

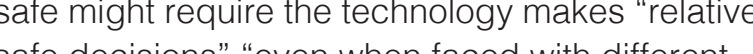
safe decisions" "even when faced with different

Finally, two documents coded for the "safety" principle specifically call for the development of safety regulations to govern Al. One call relates

${ }^{136}$ Future of Life Institute (n 90) (See Principle 2); Smart Dubai ( $n$ 23) p. 9.

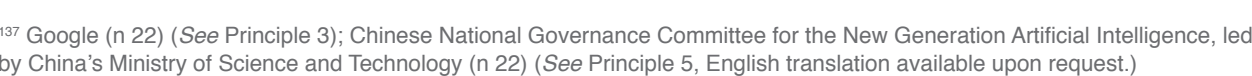

138 Information Technology Industry Council (n 9) p. 3; Smart Dubai (n 23) p. 9 . Think 20 (n 39 ) p. 7.

199 European Commission's High-Level Expert Group on Artificial Intelligence ( $n$ 6) p. 17.

100 Telia Company (n 57) (See Principle 6); Think 20 (n 39) p. 7; Google (n 23) (See Principle 3.)

"4l Future of Life Institute (n 90) (See Principle 2); Smart Dubai (n 23) p. 9 .

42T Telia Company (n 56) (See Principle 6.)

(43 Google (n 22) (See Principle 3.)

“European Comminssion's High-Level Expert Group on Artificial Intelligence (n 6 ) pp. 16-17; Organisation for Economic Co-operation and Development

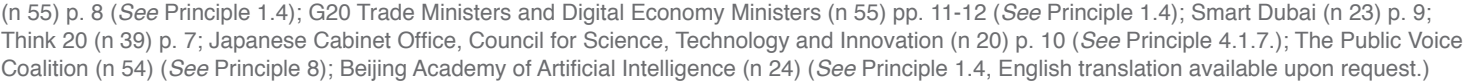

"45 Partnership on Al (n 94) p. 6 .

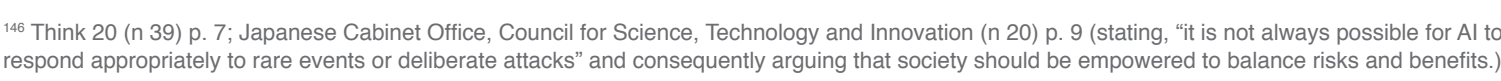

"Standard Administrtration of China (n 23) (See Principle 3.3.1.)

4 Standard Administration of China (n 23) (See Principle 3.3.1)

specifically to the regulation of autonomous

vehicles ${ }^{149}$ and the other is more general, calling

for high standards in terms of salety and product

liability" ${ }^{\prime 50}$ within the EU. Other documents call for

public awareness campaigns to promote safety.

For example, IEEE's Ethically Aligned Design

suggests that "in the same way police officers

have given public safety lectures in schools

for years; in the near future they could provide

workshops on safe [Al systems]."152

\section{Security}

The principle of "security" concerns an Al

system's ability to resist external threats. Much

of the language around security in our dataset

is high level, but in broad terms, the documents

coded here call for three specific needs to protect

against security threats: the need to test the

resilience of Al systems; ${ }^{153}$ to share information

on vulnerabilities ${ }^{154}$ and cyberattacks; 155 and

to protect privacy 156 and "the integrity and

confidentiality of personal data." 157 With regard to

the latter need, the ITI AI Policy Principles suggest that the security of data could be achieved through anonymization, de-identification, or aggregation and they call on governments to "avoid requiring companies to transfer or provide access to echnology, source code, algorithms, or encryption Cys as condilions for doing business." Chinese White Paper on Al Standardization suggests that the implementation of security assurance requirements could be faclitated through a clear distribution of liability and fault between developers, product manufacturers, service providers and end users. ${ }^{159}$

A number of documents, concentrated in the private sector, emphasize the "integral" 160 role of security in fostering trust in Al systems. ${ }^{161}$ The ITI Al Policy Principles state that Al technology's success depends on users' "trust that their personal and sensitive data is protected and handled appropriately." ${ }^{162}$

\section{Security by Design}

The "security by design" principle, as its name suggests, is related to the development of secure Al systems. The European High Level Expert Group guidelines observes that these "values-
WUnited States Executive Office of the President National Science and Technology Council Committee on Technology (n 59) p. 17.

(15) 15

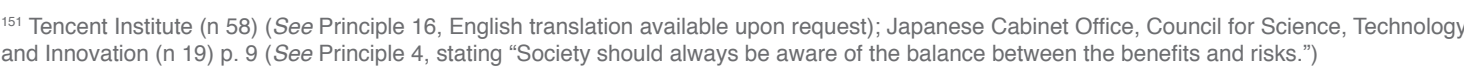

"21 IEEE Giobal Initiative on Ethics of Autonomous and Intelligent Systems (n 5) D. 31 (See Priniple 5)

sos Google (n 22) (See Principle 3.)

University of Montreal (n 34) p. 15 (See Principle 85 )

155 Information Technology Industry Council (n 8) p. 4.

39) p. 20; Information Technology Industry Council (n 9) p. 4; Europeanc

"6niversity of Montreal (n 34) p. 15 (See Principle 8.4.

t5i Information Technology Industry Council (n 8) p. 4.

Standard Administration of China (n 23) (See Principle 3.3.1)

Non Intormation Technology Industry Council ( $\mathrm{n}$ ) p. 4

161 See 1A Latam (n 23) (See Principle 10, English transtation available upon request); Telefónica (n 63) (Seee Principle 4); The Public
Voice Coalition (n 54) (See Principle 9); Telia Company (n 57 ) (See Principle 6); Google (n 23) (See Principle 3.)

"2I Information Technology Industry Council (n) B) P.4 
by-design" principles may provide a link between abstract principles and specific implementation decisions. ${ }^{163}$

A few documents argue that existing and widely adopted security standards should apply for the development of Al systems. The German A Strategy suggests that security standards for critical IT infrastructure should be used ${ }^{164}$ and the Microsoft Al Principles mention that principles from other engineering disciplines of robust and fail-safe design can be valuable. ${ }^{165}$ Similarly, the European High Level Expert Group guidelines argue for Al systems to be built with a "fallback plan" where in the event of a problem, a system would switch its protocol "from statistical to ruebased" decisior of a human before continuing ${ }^{160}$

\section{Predictability}

The principle of "predictability" is concisely

defined in the European High Level Expert Group guidelines, which state that for a system to be

predictable, the outcome of the planning process

must be consistent with the input. Predictability

is generally presented as a key mechanism

onsure that Al systems have not been

compromised by external actors. As the German

Al strategy puts it, "transparent, predictable and

verifiable" Al systems may "effectively prevent

distortion, discrimination, manipulation and other forms of improper use."168 As in the "security" principle, there is an observable connection between predictable Al systems and public trust, with the Beijing Al Principles observing that improving predictability, alongside other "ethica design approaches" should help "to make the system trustworthy."

\subsection{Transparency and Explainability}

Perhaps the greatest challenge that $\mathrm{Al}$

poses from a governance perspective is the complexity and opacity of the technology. Not only can it be difficult to understand from a echnical perspective, but early experience has already proven that it's not always clear when an Al system has been implemented in a given context, and for what task. The eight principles within the theme of Transparency and Explainability are a response to these challenges: "transparency," "explainability " "open source data and algorithms,"

"open government procurement," "right to information," "notification when interacting with an Al," "notification when Al makes a chision about an individual," and "regular reporting." The principles of transperency explainability are some of the most frequenty explaining individual principles in our datasty cecur mentioned in approximately threequer

It is interesting to note a bifurcation among the principles under this theme, where some including "explainability" and the ability to be notified when you are interacting with an $\mathrm{Al}$ or subject to an automated decision are responses to entirely new governance challenges posed by the specific capabilities of current and emerging Al technologies. The rest of the principles in this theme, such as "open source data and algorithms" and "regular reporting" are well-established pillars of technology governance, now applied specifically to Al systems.
PRINCIPLES UNDER

THIS THEME

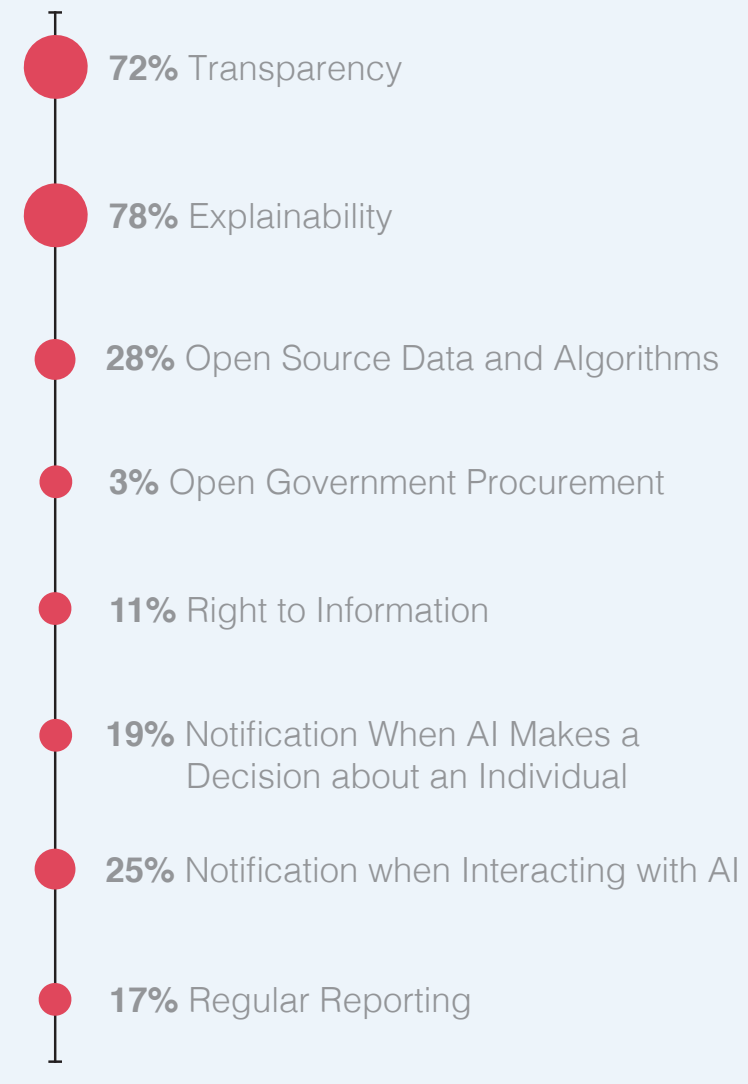

Percentage reflects the number of documents Petaset that include each principle 
Transparency and Explainability is connected to numerous other themes, most especially Accountability, ${ }^{171}$ because principles within it may function as a "prerequisite for ascertaining that [such other] principles are observed." 172 It is also connected to the principle of predictability within the Safety and Security theme and to the Fairness and Non-discrimination theme. ${ }^{173}$ The German government notes that individuals can only determine if an automated decision is biased or discriminatory if they can "examine the basis - the criteria, objectives, logic - upon which the decision was made." "Th Transparency and Explatic principles.

\section{Transparency}

The principle of "transparency" is the assertion that Al systems should be designed and implemented in such a way that oversight of their operations are possible. The documents in he dataset vary in their suggestions about how ansparency might be applied across institution and technical systems throughout the Al lifecycle. The European High Level Expert Group guidelines note that transparency around "the data, the system, and the business models" all matter. ${ }^{175}$
Some documents emphasize the importance of echnical transparency, such as providing the relevant authorities with access to source code. ${ }^{176}$

Transparency throughout an Al system's life cycle means openness throughout the design, development, and deployment processes. While most documents treat transparency as binary that is, an Al system is either transparent or it is not - several articulate the transparency principle as one that entities will strive for, with increased disclosure over time. ${ }^{177}$ Some raise concerns about the implications of an over-broad transparency regime, which could give rise to conflicts with privacy-related principles. 178 IEEE's Ethically Aligned Design recommends the development of "new standards that describe me development of "new evels of transparency, so that systems can be determined "179 where sufficient of compliance cannined. Where sufficient transparency cannot be ach "ved, the Toronto Declaration calls up in stigh-risk contexts." 1000

\section{Explainability}

"Explainability" is defined in various ways, bu is at its core about the translation of technica

"2" See, e.g., Mission assigned by the French Prime Minister ( $\mathrm{n}$ ) p. 38

12 UNI Global Union (n 66) p.7 ( See Principle 1)

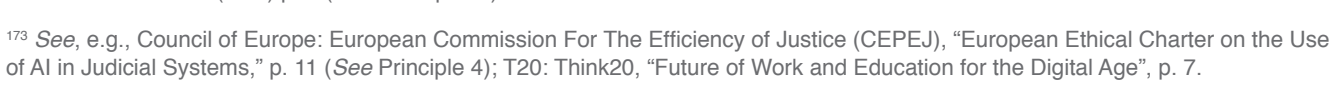

174 German Federal Ministry of Education and Research, the Federal Ministry for Economic German Federal Ministry of Education and
Research, the Federal Ministry for Economic Aftairs and Energy, and the Federal Ministry of Labour and Sociala Affairs (n 10) p. 38.

${ }^{15}$ European Commission's High-Level Expert Group on Artificial Intelligence (n 6 ) p. 18.

176 University of Montreal ( 34 ) (See Principle 5.3 , stating: "IClode for algorithms, whether public or private, must always
be accessible to the relevant public authorities and stakeholdders for verification and control purposes:")

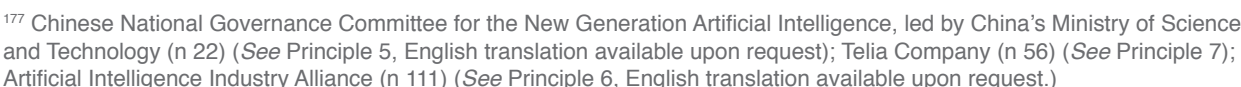

17r See, e.g., Monetary Authority of Singapore (n 37 ) p. 12 (See Principlel 8.1, stating: "excessive transparency
could create confusion or unintended opportunities for individuals to exploit or manipulate.")

to EEEE Giobal Initiative on Ethics of Autonomous and Intelligent Systems (n 5) p. 28.

${ }_{180}$ Amnesty International, Access Now (n 55) p. 9 concepts and decision outputs into intelligible, ${ }^{18}$
comprehensible formats suitable for evaluation. The T20 report on the future of work and education, for example, highlights the importance of "clear, complete and testable explanations of what the system is doing and why."182 Put another way, a satisfactory explanation "should take the same form as the justification we would demand a human making the same kind of decision." ${ }^{183}$

Many of the documents note that explainability is particularly important for systems that might "cause harm," 184 have "a significant effect on individuals," 185 or impact "a person's life, quality of life, or reputation." "186 The Al in the UK document suggests that if an Al system has a "substantial impact on an individual's life" and cannot provide "full and satisfactory explantion" for its decions, then the system should not be deployed ${ }^{187}$

The principle of explainability is closely related to the Accountability theme as well as the principle un "night to human review of a under the Human Control or Technology theme. The Toronto Declar a necessary requirement to "effectively scrutinize" the impact of Al systems on "affected individuals and groups," to establish responsibilities, and to hold actors to account. 189 The European Commission's policy statement also connects explainability to the principle of nondiscrimination, as the development of understandable $\mathrm{Al}$ is crucia for minimizing "the risk of bias or error." 1900 need for explainability will become increasingly important as the capabilities and impact of $\mathrm{Al}$ systems compound. ${ }^{19}$

\section{Open Source Data and Algorithms}

lgorithms" is, as noted in the introduction to this theme, a familiar concept in technology governance, and it operates similarly in the contex of Al as in other computer systems. The majority f documents that aldress it emphasize the value of the development of common open research and collaboration to support the open research and collaboration to support the dection describes this as " "socially equiab Declaration describes this as a "socially equitable objective "ror and the Beijing Al Principles note that open source solutions may be useful "to avoid of A deveropment to the to share the benerts

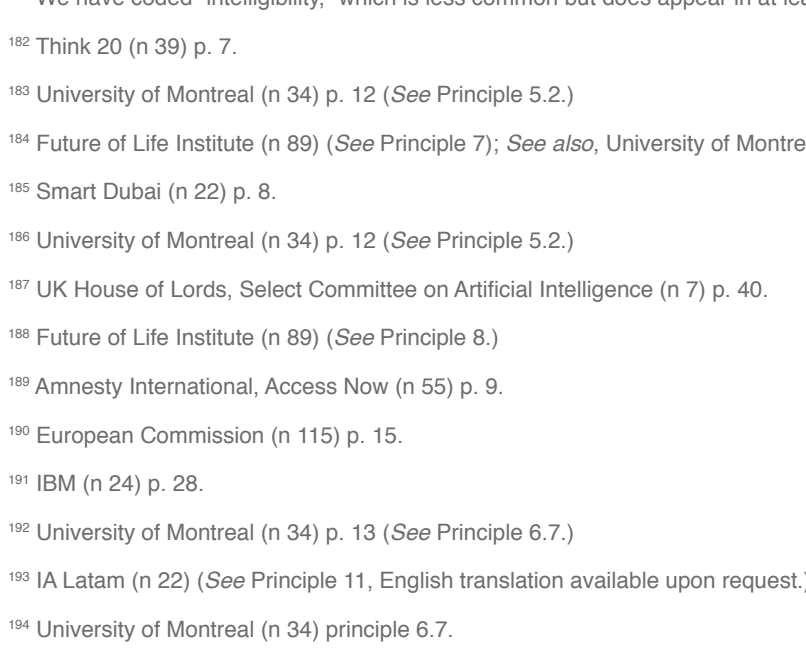


to promote equal development opportunities for different regions and industries." ${ }^{195}$ Furthe numerous documents also call for public and private investment in open datasets. ${ }^{196}$

The T20 report on the future of work and education focuses on the balance between transparency and the potential negative effect of open source policies on algorithmic innovation. One solution, they posit, is "algorithmic verifiability", which would "require companies to disclose information allowing the effect of their algorithms to be independently assessed, but not the actual code driving the algorithm." ${ }^{197}$ Recognizing that data or algorithm disclosure is not sufficient to achieve transparency or explainability, the IEEE stresses the importance of disclosing the underlying algorithm to validation or cesing the underlying algoith to validetion or certication agoncies that can accountability bodies 198

\section{Open Government Procurement}

"Open government procurement," the requirement that governments be transparent about their use of Al systems, was only present in one document in our dataset. The Access Now report recommends that: "When a government body seeks to acquire an Al system or components thereof, procuremen should be done openly and transparently

according to open procurement standards.

This includes publication of the purpose of the

system, goals, parameters, and other information to facilitate public understanding. Procurement should include a period for public comment, and states should reach out to potentially affected groups where relevant to ensure an opportunity to input." ${ }^{199}$

It is notable that the Access Now report is one of the few documents in our dataset that specifically adopts a human rights framework. This principle accounts for the special duty of governments under Principle 5 of the UN Guiding Principles on Business and Human Rights to protect against. human rights abuses when they contract with

private businesses.

\section{Right to Information}

The "right to information" concerns the entitlement of individuals to know about various aspects of the use of and their in might include "information about the personal data used in the decision-making process," 200 "access to the factors, the logic, and techniques that produced the outcome" of an Al system, 201 and generally "how automated and machine learning decision-making processes are reached."202

As elsewhere where the word "right" is contained in the title of the principle, we only coded documents where they were explicitly articulated as a right or obligation. The OECD and G20 Al principles, for instance, do not call for an explicit "right to information" for users, and thus were not coded here, even though they recommen that those adversely affected by an Al system should be able to challenge it based on "easyto-understand information on the factors, and the logic that served as the basis for the prediction, recommendation or decision." ${ }^{203}$ One documen specifically articulates the right to information as extending beyond a right to technical matter and data to the "obligation [that it] should be drawn up in plain language and be made easily accessible." ${ }^{204}$

\section{Notification when Al Makes a}

Decision about an Individual

The definition of the principle of "notification when an Al system makes a decision about individual" is facially fairly clear: where an Al has been employed the person to whom it was subject should know. The Al in UK document stresses the importance of this principle to allow individuals to "experience the advantages of $\mathrm{Al}$, as well as to opt out of using such products should they have concerns." 205 If people don't know when they are subject to automated decisions, they won't have the autonomy to decide whether or not they consent, or the information to reach their own conclusions about the overall value that $\mathrm{Al}$ provides.

In this respect, the notification principle connects to the themes of Human Control of Technology and Accountability. For example, the European
Commission not only suggests that individuals should be able to opt out, ${ }^{206}$ but also that they should be "informed on how to reach a human and how to ensure that a system's decisions can be checked or corrected,"207 which is an mportant component of accountability. Access Now emphasizes the special importance of this principle when an Al system "makes a decision that impacts an individual's rights." ${ }^{208}$

\section{Notification when Interacting with an A}

The principle of "notification when interacting with an Al system," a recognition of Al's increasing ability to pass the Turing test at least in limited applications, stands for the notion that humans should always be made aware when they are engaging with technology rather than directly with nother person. Examples of when this principle another person. Examples of when this principle recognition systems, credit scoring systems, and recognilion systems, credit scoring systems, and

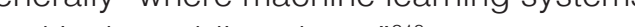

Like "notification when an Al system makes a decision about an individual," this principle is a precondition to the actualization of other principles, including in the Accountability and Human Control of Technology themes. However, this principle is broader than the preceding one because it requires notification even in passive uses of Al systems. In the deployment of facial recognition systems, for example, the "decision" 


\subsection{Fairness and Non-discrimination}

mportant "in the workplace." 2

\section{Regular Reporting}

"Regular reporting" as a principle stands for

the notion that organizations that implement Al

systems should systematically disclose important

formation about their use. This might include

"how outputs are reached and what actions are

taken to minimize rights-harming impacts," 213

"discovery of ... operating errors, unexpected or undesirable effects, security breaches, and data leaks, "or the "evaluation of the effectiveness" of Al systems. The regular reporting principle mechanism for transparency and explainability mechanism for transparency and explainabilty. and the OECD and G2O Al principles further call for governments to step in and develop

internationally comparable metrics to measure

research, development, and deployment and to

gather the necessary evidence to support these

claims. ${ }^{210}$

Algorithmic bias - the systemic under- or overprediction of probabilities for a specific population - creeps into Al systems in a myriad of ways. A system might be trained on unrepresentative flawed, or biased data. ${ }^{217}$ Alternatively, the predicted outcome may be an imperfect proxy for the true outcome of interest ${ }^{218}$ or the outcome of interest may be influenced by earlier decisions that are themselves biased. As Al systems increasingly inform or dictate decisions, particularly in sensitive contexts where bias long predates their introduction such as lending, healthcare, and criminal justice, ensuring fairness and nondiscrimination is imperative. Consequently, the hirness and Non-discrimination theme is the every recument referene in our dataset, with principles: "non-discrimination and the preventix p bias" " "epresentative and high-qualiy data," "fias, " " "epresentative "inclusiveness in impac," and "inclusiveness in design "219

Within this theme, many documents point to biased data - and the biased algorithms it generates - as the source of discrimination and unfairness in Al, but a few also recognize the role unfairness in Al, but a few also recognize the role or preventing discriminatory or otherwise harmful r preventing discriminatory or otherwise harmif the tec. Examples of language that focuses Rules for Al conference paper ("[C]ompanies ${ }^{213}$ Access Now (n 9) p.33.

University of Montreal ( $n 34)$ p. 12 (See Principle 54,

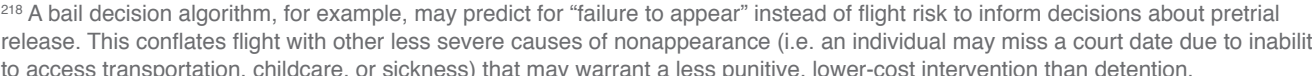

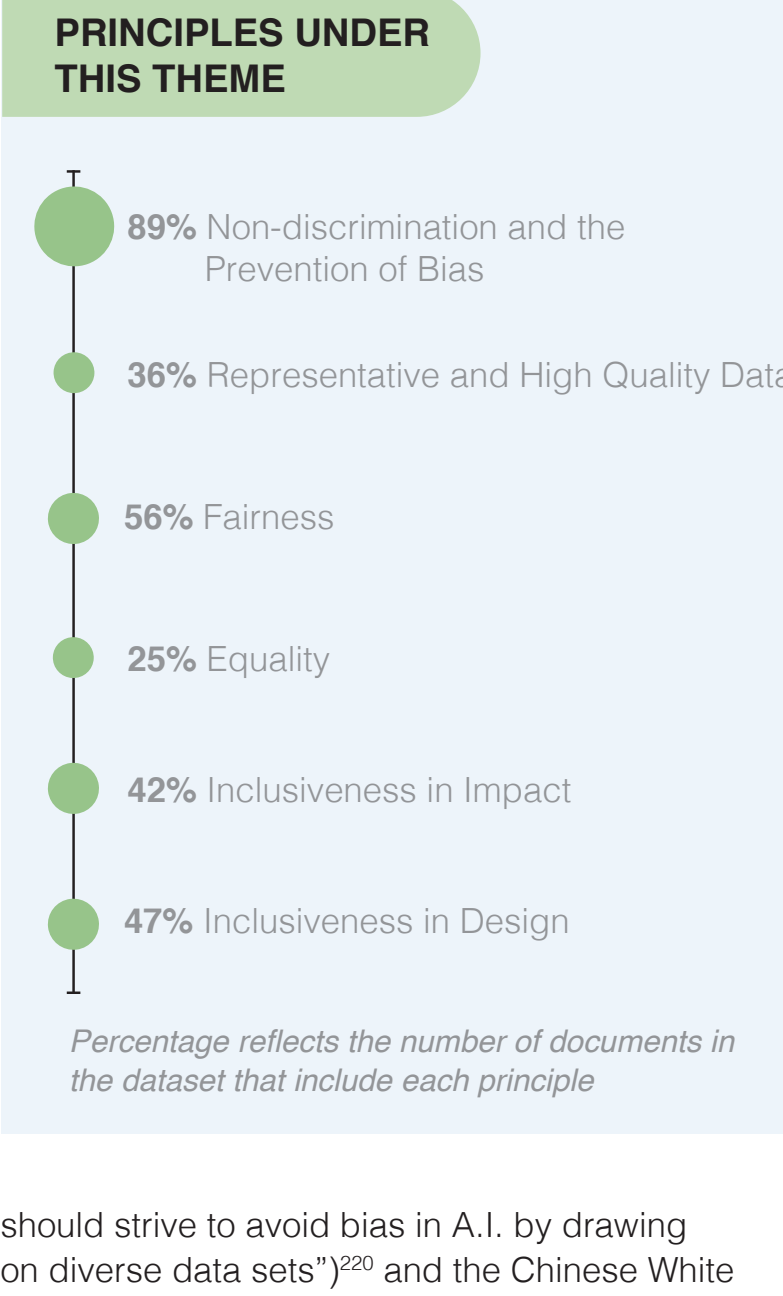

should strive to avoid bias in A.I. by drawing on diverse data sets" ${ }^{220}$ and the Chinese White Paper on Al Standardization ("we should also 
be wary of Al systems making ethically biased decisions"). ${ }^{221}$ While this concern is warranted it points toward a narrow solution, the use of unbiased datasets, which relies on the assumption that such datasets exist. Moreover, it reflects a potentially technochauvinistic orientation - the id that technological solutions are appropriate and adequate fixes to the deeply human problem of bias and discrimination. ${ }^{222}$ The Toronto Declaration takes a wider view on many places bias permeates the design and deployment of Al systems:

All actors, public and private, must preven and mitigate against discrimination risks in the design, development and application of machin learning technologies. They must also ensure that there are mechanisms allowing for access to hat the are mechanisms must also ensure throughout a systen's lifecycle.

Within the Fairness and Non-discrimination theme, we see significant connections to the Promotion of Human Values theme, with principles such as "fairness" and "equality" sometimes appearing alongside other values in lists coded under the "Human Values and Human Flourishing" principle. ${ }^{224}$ There are also connections to the Human Control of Technology, and Accountabit
themes, principles under which can act as mplementation mechanisms for some of the higher-level goals set by Fairness and Nondiscrimination principles

\section{Non-discrimination and the Prevention of Bias} The "non-discrimination and the prevention of bias" principle articulates that bias in $\mathrm{Al}$ - in the training data, technical design choices, or the technology's deployment - should be mitigated to prevent discriminatory impacts. This principle was one of the most commonly included ones in and "equality" frequently operates as a high-leve objective for which other principles under this deta" and "inclusiveness in design") (unclion as implementation mechanisms

Deeper engagement with the principle of "nondiscrimination and the prevention of bias" included warnings that $\mathrm{Al}$ is not only replicating existing patterns of bias, but also has the potential to significantly scale discrimination and to discriminate in unforeseen ways. ${ }^{227}$ Other documents recognize that Al's great capacity for classification and differentiation could and should be proactively used to identify and address discriminatory practices in current systems. ${ }^{228}$ The German Government commits to assessing how its current legal our dataset ${ }^{225}$ and, along with others like "fairness" theme (such as "representative and high-quality

21 Standard Administration of China (n 23) (See Principle 3.3.2.)

M. Broussard coined the term "technochauvinism" in her recent book

${ }^{20}$ Amnesty International, Access Now (n 55) p.6 (SeeP Principele 17.)

2ex Organisation for Economic Co-operation and Development (n 54$)$ p. 7 (See Principle 1.2.
G20 Trade Ministers and Digital Economy Ministers (n 54) p. 11 (See Principle 1.2.)

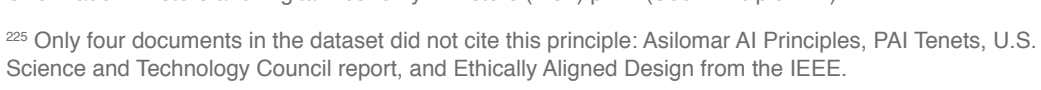

26 European Commission (n 115) p. 13

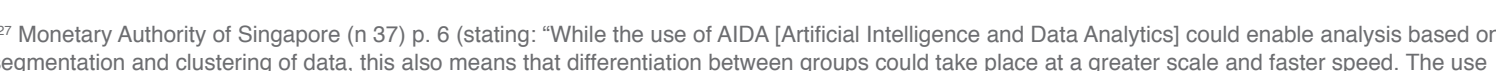

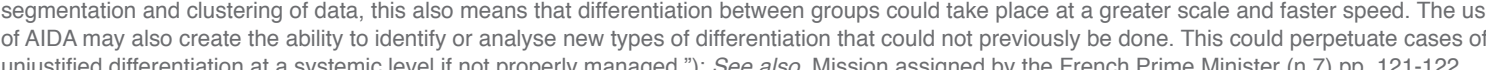

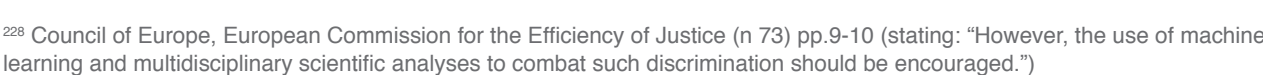

protections against discrimination cover - or fail to cover - Al bias, and to adapt accordingly.

\section{Representative and High Quality Data}

The principle of "representative and high quality data," driven by what is colloquially referred to as the "garbage in, garbage out" problem, is defined as the use of appropriate inputs to an Al system, which relates accurately to the population of interest. The use of a dataset that is not representative leads to skewed representation of a group in the dataset compared to the actual composition of the target population, introduces bias, and reduces the accuracy of the system's eventual decisions. It is important that the data be high quality and apposite to the context in which the Al system wil be deployed, because a representative datam wil may nonethe be infor may nonelheloss be in a come qualiy mea in consistency, and valy As the definilon suggests of mitigating the discriminatory impacts of $A$

The Montreal Declaration and the European Charter on Al in judicial systems call for representative and high quality data but state that even using the gold standard in data could be detrimental if the data are used for "deterministic analyses."231 The Montreal Declaration's articulation of this principle warns against using data to lock individuals into a user profile, fix their personal identity, or confine them to

20" German Federal Ministry of Education and Research, the Federal Ministry for Economic Aftairs

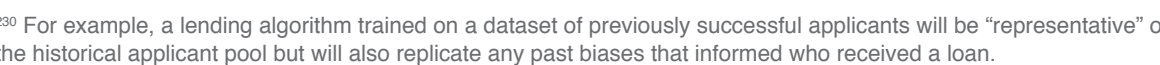

- Council of Europe, European Commission for the Efficiency of Justice (n 73) p. 9.

${ }^{32} 2$ University of Montreal (n 34) p.14 (See Principle 7.4.

al Intelligence $(n 6)$.

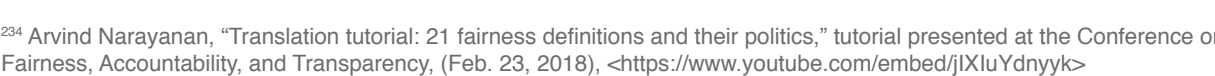

${ }_{45}^{45}$ Microsoft (n 27) p. 58. a filtering bubble, which would restrict and confine heir possibilities for personal development." ${ }^{232}$ Som documents, including the European Charter on Al in judicial systems, explicitly call for special protections or marginalized groups and for particularly sensitive data, defined as "alleged racial or ethnic origin, background, political opinions, eligious or philosophical beliefs, trade union

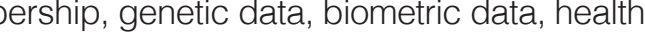
elated data or data concerning sexual life or sexual

The "fairness" principle was defined as equitable and impartial treatment of data subjects by $\mathrm{Al}$ systems. We used this definition, drawn from common usage over a technical one because articulations of fairness in the documents coded under this principle are not especially technical overly specific in spite of the rich vein of academic ove re airness ${ }^{234}$ However, Microsoft adds to its princip "Al systems should treat all people farly" in purpe "elaboration that "industry and aco fairly" the furth conting the should antical

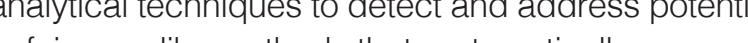
unstictictly assess train Al systems for appropriate its origins and characteristics." 235 
There was general consensus in the documents about the importance of fairness with regard to marginalized populations. For example, the Japanese Al principles include the imperative that "all people are treated fairly without unjustified discrimination on the grounds of diverse backgrounds such as race, gender, nationality, age, political beliefs, religion, and so on." ${ }^{236}$ Similarly, the Chinese Al Industry Code of Conduct states that "[t]he development of artificia intelligence should ensure fairness and justice, avoid bias or discrimination against specific groups or individuals, and avoid placing disadvantaged people at a more unfavorable position." 237 The European High Level Expert Group guidelines term this the "substantive dimension" of fairness, and also point to a "procedural dimension of fain

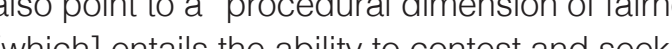
[Which ent systems and by the humans operating them." which systems and by the humans operaling them," which the Accountability theme.

\section{Equality}

perinciple of "equality" stands for the idea that people, whether similarly situated or not, deserve the same opportunities and protections with the rise of Al technologies. "Equality" is similar to "fairness" but goes farther, because of fairness's focus on similar outcomes for similar inputs. As the European High Level Expert Group guidelines puts it:

"Equality of human beings goes beyond nondiscrimination, which tolerates the drawing of distinctions between dissimilar situations based on objective justifications. In an Al context,

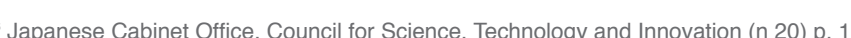

"Artificial Intelligence Industry Alliance (n 111) (See Principle 3, English translation available upon request.

European Commission's Hign-Level Expert Group on Afticial Intelligence ( $n$ 6) p.7.

${ }^{n a}$ Amnesty International, Access Now (n 55) pp. 5, 10.

200. European Commission's High-Level Expert Group on Artificial Intelligence (n 6) p. 18

244 University of Montreal (n 34) p. 13 (See Principles 6.2 and 6.3 ) equality entails that the same rules should apply for everyone to access to information, data, knowledge, markets and a fair distribution of the value added being generated by technologies." 238

There are essentially three different ways that equality is represented in the documents in our dataset: in terms of human rights, access to technology, and guarantees of equal opportunity hrough technology. In the human rights framing, the Toronto Declaration notes that Al will pose "new challenges to equality" and that "[s]tates have do duty to take proactive measures to eliminate framing documents deserve access to the benefits of Al techno and that systems should be designed to facilitate that broad access. ${ }^{240}$

Documents that take on what we have termed De guarantees of equal opportunity framing go bit farther in their vision for how Al systems may or should implement equality. The Montreal Declaration asserts that Al systems "must help eliminate relationships of domination between groups and people based on differences of power, wealth, or knowledge" and "must produce social and economic benefits for all by reducing social inequalities and vulnerabilities."241 This framing makes clear the relationship between the "equality" principle and the principles of "non-discrimination and the prevention of bias" and "inclusiveness in impact."

\section{Inclusiveness in Impact}

act" as a principle calls for a just distribution of Al's benefits, particularly to populations that have historically been excluded. There was remarkable consensus in the language that documents employed to reflect this principle, including concepts like "shared benefits" and "empowerment":

\begin{tabular}{|c|c|}
\hline Document & Language of principle \\
\hline Asilomar Al Principles & $\begin{array}{l}\text { Shared Benefit: Al technologies should benefit and } \\
\text { empower as many people as possible. }{ }^{242}\end{array}$ \\
\hline $\begin{array}{l}\text { Microsoft's Al } \\
\text { principles }\end{array}$ & $\begin{array}{l}\text { Inclusiveness - Al systems should empower everyone and engage } \\
\text { people. If we are to ensure that Al technologies benefit and empower } \\
\text { everyone, they must incoroporate and address a broad range of } \\
\text { human needs and experiences. Inclusive design practices will help } \\
\text { system developers understand and address otential barriers in a } \\
\text { product or environment that could unintentionally exclude poople. } \\
\text { This means that Al systems should be designed to understand the } \\
\text { context, needs and expectations of the people who use them. }{ }^{243}\end{array}$ \\
\hline $\begin{array}{l}\text { Partnership on } \\
\text { Al Tenets }\end{array}$ & $\begin{array}{l}\text { We will seek to ensure that Al technologies benefit } \\
\text { and empower as many people as possible }{ }^{244}\end{array}$ \\
\hline $\begin{array}{l}\text { Smart Dubai Al } \\
\text { principles }\end{array}$ & $\begin{array}{l}\text { We will share the benefits of Al throughout society: Al should } \\
\text { improve society, and society should be consulted in a } \\
\text { representative fashion to inform the development of Al245 }\end{array}$ \\
\hline $\begin{array}{l}\text { T20 report on the } \\
\text { future of work } \\
\text { and education }\end{array}$ & $\begin{array}{l}\text { Benefits should be shared: Al should benefit as many people } \\
\text { as possible. Access to Al technologies should be open to all } \\
\text { countries. The wealth created by Al should benefif torkers } \\
\text { and society as a whole as well as the innovators. }\end{array}$ \\
\hline $\begin{array}{l}\text { UNI Global Union's } \\
\text { Al principles }\end{array}$ & $\begin{array}{l}\text { Share the Benefits of AI Systems: Al technologies should } \\
\text { benefit and empower as many people as possible. The } \\
\text { economic prosperity created by Al should be distributed } \\
\text { broadly and equally, to benefit all of humanity. }{ }^{247}\end{array}$ \\
\hline
\end{tabular}

The European High Level Expert Group guidelines add some detail around what "benefits" might be shared: "Al systems can contribute to wellbeing by seeking achievement of a fair, inclusive and peaceful society, by helping to increase citizen's mental autonomy, with equal distribution of economic, social and political opportunity." ${ }^{24}$ There is a clear connection to the principles we have catalogued under the Promotion of Human Values theme, especially the principle of "leveraged to benefit society.

\footnotetext{
22: Future of Life Institute (n 89) (See Principle 14)

23. Microsoft (n 26) p. 69 .

${ }^{24}$ Parthership on Al (n 93) (Principle 1,

${ }^{245}$ Smart Dubai (n 22) p. 1

246 Think 20 (n 38) p. 7

${ }^{247}$ UNI Global Union (n 65) p. 8 ( See Principle 6 ,

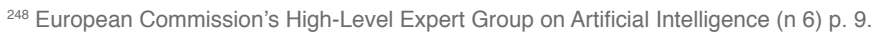




\section{Inclusiveness in Design}

The "inclusiveness in design" principle stand for the idea that ethical and rights-respecting Al requires more diverse participation in the development process for Al systems. This principle is expressed in two different ways. The first and more common interpretation calls for diverse Al design teams. For example, the Al for Europe document from the European Commissio affirms that "More women and people of diverse backgrounds, including people with disabilities, need to be involved in the development of Al, starting from inclusive Al education and training in order to ensure that $\mathrm{Al}$ is non-discriminatory and inclusive."249 The European High Level Expert and inclusive." Gry diverse in terms of gender, culture, age but also in terms of professional backgrunds and skil sets." 250

The second interpretation holds that a broad cross-section of society should have the

opportunity to weigh in on what we use Al for and in what contexts; specifically, that there should be a genuinely diverse and inclusive social forum for discussion, to enable us to democratically determine which forms of Al are appropriate for our society. ${ }^{251}$ The Toronto Declaration emphasizes the importance of including end users in decisions about the design and implementation of $\mathrm{Al}$ in order to "ensure that systems are created and used in ways that respect rights - particularly the rights of marginalised groups who are vulnerable to discrimination." "252 This interpretation is similar to the Multistakeholder Collaboration principle in our Professional Responsibility category, but it differs in that it emphasizes bringing into conversation all of society specifically those most impacted by Al - and not just a range of professionals in, for example, industry, government, civil society organizations, and academia.

\subsection{Human Control of Technology}

From prominent Silicon Valley magnates' concerns bout the Singularity to popular science fiction dystopias, our society, governments, and companies alike are grappling with a potential shift in the locus of control from humans to $\mathrm{Al}$ systems. Thus, it is not surprising that Human Control of Technology is a strong theme among the documents in our dataset, ${ }^{253}$ with significant representation for the three principles that fall under it: "human review of automated decision," "ability to opt out of automated decision," and "human control of technology (other/general)."

There are connections between the principles in the Human Control of Technology theme and a number of other themes, because human involvement is often presented as a mechanism to tacilate objectives within the them of Safety and Security, Transparency and Explar Sabety Faineous and Nronsparcimination and the Falmess and Non-discrimination, and the OECD and GOM Al principles rofer to he, the OECD and G20 Al principles refer to human control as a "safeguard" 254 and UNI Global Union claims that transparency in both decisions and outcomes requires the right to appeal decisions made by Al/algorithms, and having it reviewed by a human being." ${ }^{255}$

Human Review of Automated Decision The principle of "human review of automated decision" stands for the idea that where Al systems are implemented, people who are subject

\section{PRINCIPLES UNDER \\ THIS THEME}

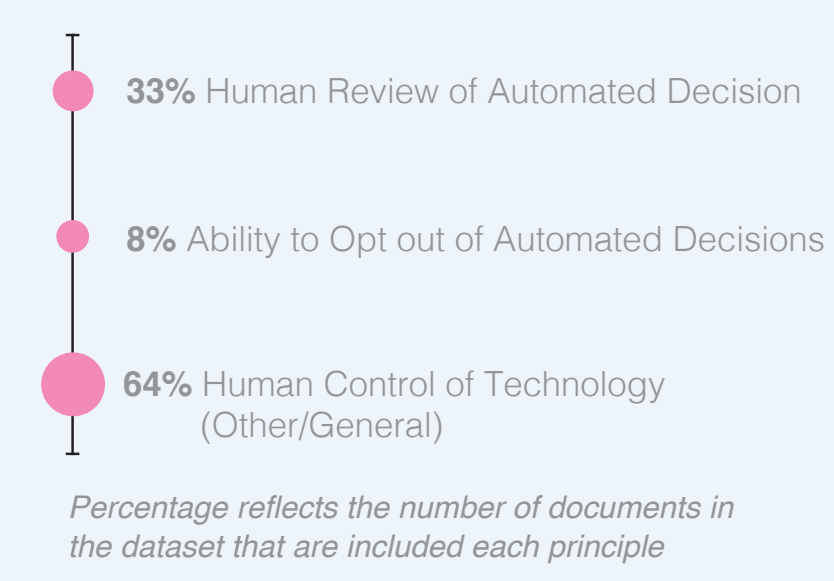

o their decisions should be able to request and receive human review of those decisions. In contrast to other principles under this theme, the "human review of automated decision" principle is always ex post in is implementation, providing the opportunity to remedy an objectionable result. Although the documents in our datase are situated in a variety of contexts, there is remarkable commonality between them in the articulation of this principle. The underlying rationale, when explicit, is that "Humans interacting with Al systems must be able to keep full and effective self-determination over themselves."25 
The most salient differences among the documents are in the breadth of circumstances in which they suggest that human review is appropriate, and the strength of the recommendation. Many of the documents apply the principle of human review in all situations in which an Al system is used, but a handful constrain its application to situations in which the decision is "significant." ${ }^{257}$ Further, the principles generally present human review as desirable, but two documents, the Access Now report and the Public Voice Coalition Al guidelines, articulate it as a right of data subjects. The European Charter on Al in judicial systems also contains a strong version of the human review principle, specifying that if review is requested the case should be heard by a competent court. 250

\section{Ability to Opt out of Automated Decision} The "ability to opt out of automated decision" principle is defined, as its title suggests, as affording individuals the opportunity and choice not to be subject to Al systems where they are implemented. The Al sh he UK document explains its relevance by saying:

"It is important that members of the public are aware of how and when artificial intelligence is being used to make decisions about them, and what implications this will have for them personally. This clarity, and greater digital understanding, will help the public experience the advantages of $\mathrm{Al}$, as well as to opt out oducts should they have concerns." 259

Commission for the Efficiency of Justice (n 73) p.

ra UK House of Lords, Select Committee on Atrificial Intelligence (n 8$)$ p. 27.

so Smart Dubai (n 23) p. 2 20.

European Commission's High-Level Expert Group on Artiticial Intelligence (n 6) p. 12

25 $64 \%$ of documents included the thuman control of technology (other/general)" principe.

$20 \times 5$ Future of Life Institite (n 89) (See Principle 16.)
Of course, individuals interact with Al systems in numerous ways: their information may be used as training data; they may be indirectly impacted by systemic deployments of Al, and they may be personally subject to automated decisions. Perhaps because these principles are articulated with relative brevity, or perhaps because of the significant challenges in implementation, only three documents contained this principle: $\mathrm{Al}$ in the UK, the European High Level Expert Group guidelines, and the Smart Dubai Al principles. All documents articulated this principle as a natural corollary of the right to notification when interacting with an Al system. The latter two documents disagree about the extent of the principle's mplementation, with Smart Dubai saying the entities should "consider" providing the ability to opt out "where appropriate" 260 and the European "

\section{Human Control of Technology}

\section{Other/General)}

pre "human control of technology (other/general)" principle requires that Al systems are designed and implemented with the capacity for people to intervene in their actions. This was the most commonly referenced principle ${ }^{262}$ under the them of Human Control of Technology, and most of the documents that included it framed it broadly, as in our definition. The Asilomar Al principles' version is illustrative: "Humans should choose how and whether to delegate decisions to Al systems, to accomplish human-chosen objectives." ${ }^{263}$ Where he documents included a theoretical grounding for this principle, it was typically the preservation of human autonomy. For example, the Montreal Declaration states that Al systems should be bu and used "respectingt Al systems should be built the goal of increasing people's control over their lives and their surroundings." 264

Numerous documents emphasize the importance not only of human-chosen objectives, which were included in the Asilomar principle, but the Promotion of Human Values and human quality

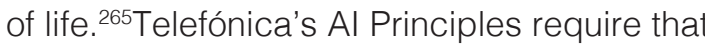
their uses of Al "be driven by value-based considerations" 266 and IA Latam's principles state that the use of Al should not only be under sta control but be for the common good ${ }^{267}$ Others focus on the stemming the capacity of Al system to be used to manipuatere or mislead peoplem

A number of private sector principles stand out for their more granular versions of this principle, which demonstrate some connection with the theme of Professional Responsibility, because they are addressed quite directly to the developers and users of Al tools. Microsoft's Al principles include multiple steps to ensure human control, including [e]valuation of when and how an Al system should seek human input during critical situations,

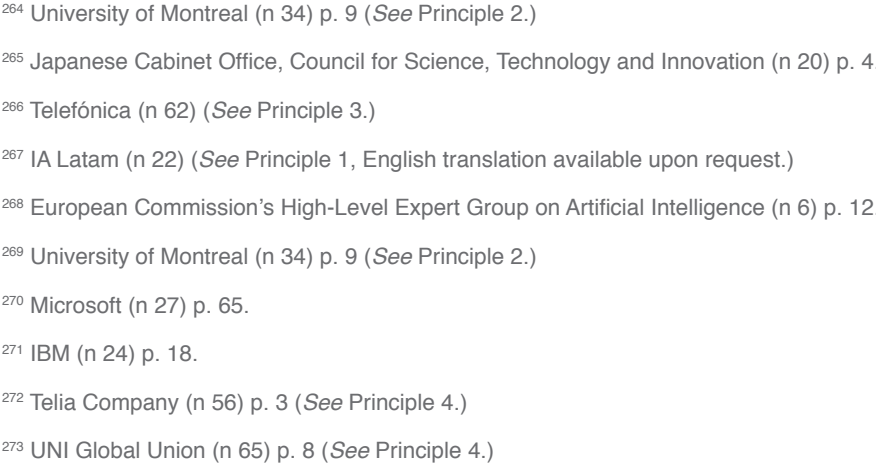

and how a system controlled by Al should transfer control to a human in a manner that is meaningful and intelligible."270 The IBM AI principles remind developers that they must identify and design for other users. The policy notes that they "may not have control over how data or a tool will be used by user, client, other external source."271 Telia's Al principles state that the company "monitor[s] Al solutions so that we are continuously ready to intervene."272

Finally, emphasizing the role of people in the process in a different way, UNI Global Union asserts that Al systems must maintain "the lega status of tools, and legal persons [must] retain control over, and responsibility for, these machines at all times."273 The Public Voice Coalition's

principle of human control extends perhaps the

farthest, explicitly stating that an institution he obligation to terminate an Al system if they are an obligation to terminate an Al syst 


\subsection{Professional Responsibility}

The theme of Professional Responsibility brings together principles that are targeted at individuals and teams who are responsible for designing, developing, or deploying Al-based products or systems. These principles reflect an understanding that the behavior of such professionals, perhaps independent of the organizations, systems, and policies that they operate within, may have a direct influence on the ethics and human rights impacts of Al. The theme of Professional Responsibility was widely represented in our dataset ${ }^{275}$ and consists of five principles: "accuracy," "responsible design," "consideration of long-term effects," "multistakeholder collaboration" and "scientific integrity."

There are significant connections between the Professional Responsibility theme and the Accountability theme, particularly with regard to the principle of "accuracy." Articulations of the principle of "responsible design" often connect with the theme of Promotion of Human Values, and sometimes suggest Human Control of

\section{Accuracy}

The principle of "accuracy" is usefully defined by the European High Level Expert Group

guidelines, which describe it as pertaining "to an Al's confidence and ability to correctly classify information into the correct categories, or its abilly to make correct predictions, recommendations, or decisions based on data or models."276 There is a split among the documents, with some

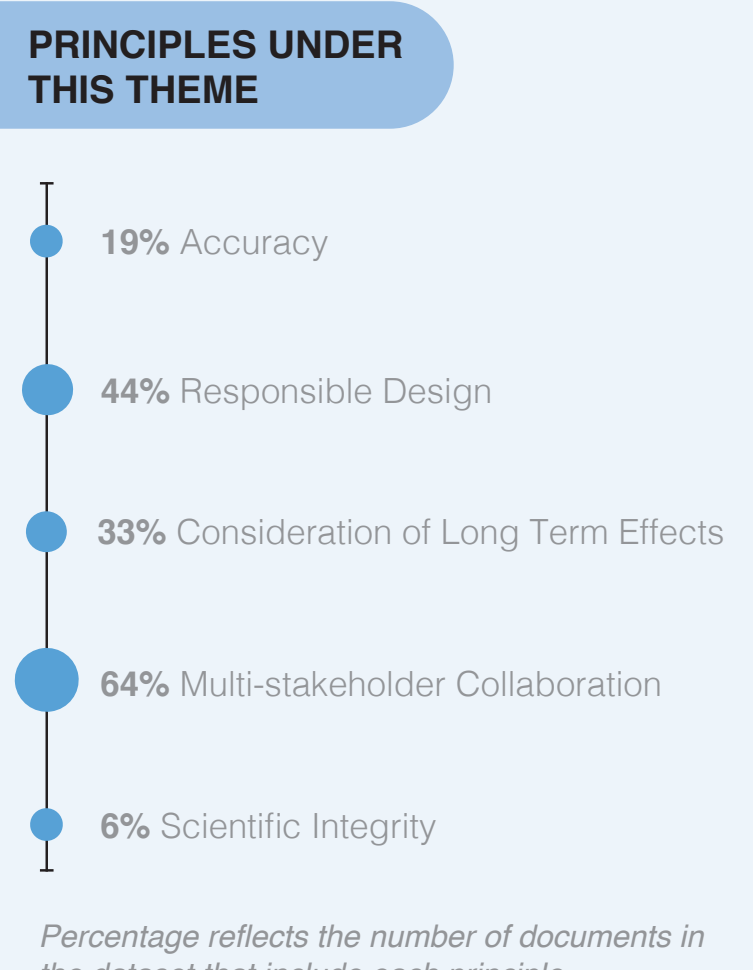

the dataset that include each principle

understanding "accuracy" as a goal and others as an ongoing process

The Google Al principles are focused narrowly on the goal of preventing the use of Al in the creation and dissemination of false information, making "accurate information readily available"277 and the Montreal Declaration similarly avers that Al "should be designed with a view to containing [the] dissemination" of "untrustworthy information." By contrast, the European High Level Expert Group guidelines are emblematic of the processbased approach, recommending that develope establish an internal definition of "accuracy" for the use case; develop a method of measurement; verify the harms caused by inaccurate predictions and measure the frequency of such predictions; and finally institute a "series of steps to increase the system's accuracy."279 In cases when inaccurate predictions cannot be avoided, these guidelines suggest that systems indicate the likelihood of such errors. ${ }^{280}$ Relying on a similar understanding of accuracy, the IEEE recommends operators measure the effectiveness of Al systems through methods that are "valid and accurate, as well as meaningful and actionable."2

The principle of accuracy is frequently referred to alongside the similar principle of "verifiability and replicability" under the Accountability theme. The Public Voice Coalition, for instance, recommends that institutions must ensure the "accuracy, eliability and validity of decisions." 282 The two can be distinguished as "accuracy" is targeted at developers and users, promoting careful attention to detail on their part. By contrast, the principle of replicability focuses on the technology, asking whether an Al system delivers consistent results under the same conditions, facilitating post-hoc evaluation by scientists and policymakers.

\section{Responsible Design}

design" stands for the notion that individuals must be conscientious and thoughtful when engaged in the design of Al systems. Indeed, even as the phrasing of this principle might differ from document to document there is a strong consensus that professionals are in a unique position to exert influence on the future of Al. The French Al strategy emphasizes the crucial role that researchers, engineers and developers play as "architects of our digital society." 283 This document notes that professionals play an especially important part in emerging technologies since laws and norms cannot. keep pace with code and cannot solve for every negative effect that the underlying technology may bring about.284

The Partnership on Al Tenets prompt research and engineering communities to "remain socially responsible, and engage directly with the potential influences of Al technologies on wider society." 285 This entails, to some degree, an obligation to become informed about society, which other documents address directly. The IBM Al principles require designers and developers not only to encode values that are sensitive to different contexts but also to engage in collaboration to better recognize existing values. ${ }^{286}$ The Tencen and Microsoft Al principles capture this idea by calling for developers to ensure that design

2is University of Montreal (n 34) p.9 (See Principle 2.5.)

"European Commission's High-Level Expert Group on Atticial l Intelligence (n 6 ) 17.

(1)

IEEE Global Initiative on Ethics of Autonomous and Intelligent Systems (n 5) p. 25 (See Principle 4)

sea The Public Voice Coallition (n 53) (See Principle 6.)

Mission assigned by the French Prime Minister (n 8$)$ p. 114 
is "aligned with human norms in reality"287 and to involve domain experts in the design and deployment of Al systems. ${ }^{288}$ We note a rare interaction among the documents when the Indian Al strategy recommends that evolving best practices such as the recommendations by the Global Initiative on Ethics of Autonomous and Intelligent Systems by IEEE be incorporated in the design of Al systems. ${ }^{2}$

\section{Consideration of Long Term Effects}

The principle of "consideration of long term

effects" is characterized by deliberate attention

to the likely impacts, particularly distant future

impacts, of an Al technology during the design

and implementation process. The documents th

address this principle largely view the potential

long-term effects of $\mathrm{Al}$ in a pluralistic manner.

For instance, the German Al strategy highlights

that $\mathrm{Al}$ is a global development and policymakers

will need to "think and act globally" while

considering its impact during the development

stage ${ }^{200}$; and the Asilomar principles recognize

hat highly-developed Al must be for the benefit

of all of humanity and not any one sub-group.

The Montreal Declaration recommends that

professionals must anticipate the increasing risk

of Al being misused in the future and incorporate

mechanisms to mitigate that risk. ${ }^{29}$

Some of the documents base their articulations of this principle on the premise that Al capabilities in the future may be vastly advanced compared to the technology we know today. The Beijing Al principles recommend that research on potentia risks arising out of augmented intelligence,

artificial general intelligence and superintelligence be encouraged. ${ }^{293}$ These documents take the position that possibility of catastrophic or existential risks arising out of Al systems in the future cannot not be ruled out and professionals must work towards avoiding or mitigating such impacts. ${ }^{294}$

\section{ultistakeholder Collaboration}

"Multistakeholder collaboration" is defined as encouraging or requiring that designers and users of Al systems consult relevant stakehold groups while developing and manaing the use of Al applications. This was the most commonly included of the principles under Professional Responsibility. 205 Broadly, the documents reflect either a toolspecific or a general policy visioct multistakeholderism.

The IBM Al principles are emblematic of a ool-specific vision, specifying that developers should try to consult with policymakers and academics as they build Al systems to bring in different perspectives. ${ }^{296}$ Additionally, the principles recommend that a feedback loop or open dialogue be established with users allowing them to highlight biases or other onground challenges that the system might bring about once deployed. ${ }^{297}$ The Toronto Declaration calls for meaningful consultation with users and especially marginalized groups during the design and application of machine learning systems. ${ }^{298}$ Access Now also suggests that human rights organizations and independent human rights and $\mathrm{Al}$ experts be included during such consultations. 299

Documents that espouse a general policy function for multistakeholderism call for collaboration across the globe, rather than around any particular tool. Participants may be drawn from universities, research institution be industry, policymaking, and the public at large in and use cases. The Japanese and Chinese and use cases. The Japanese and Chinese $A$ colategies, for instance, push for international "noperation on Al research and use, to build a non-regulatory, non-binding" framework. ${ }^{300}$ This interpretation of multistakeholderism is focused on the utility of building a normative consensus on the governance of Al technologies. This vision is also seen as a policy vehicle through which governments can educate and train their populations to ensure an easy transition and safety as labor markets continue to modernize. ${ }^{30}$

\section{Scientific Integrity}

tific integrity" means that hose who buld and implement Al systems be guided by established professional values and practices. Interestingly, both documents that include this relatively little-mentioned principle are organizations driven at least in significant part by engineers and technical experts. Google's Al principles recognize scientific method and excellence as the bedrock for technological innovation, including Al. The company makes a commitment to honor "open inquiry, intellectual rigor, integrity, and collaboration" in its endeavors ${ }^{302}$ The IEEE acknowledges the idea of scientific rigor in its call for creators of Al systems to define metrics, make them accessible, and measure systems ${ }^{303}$

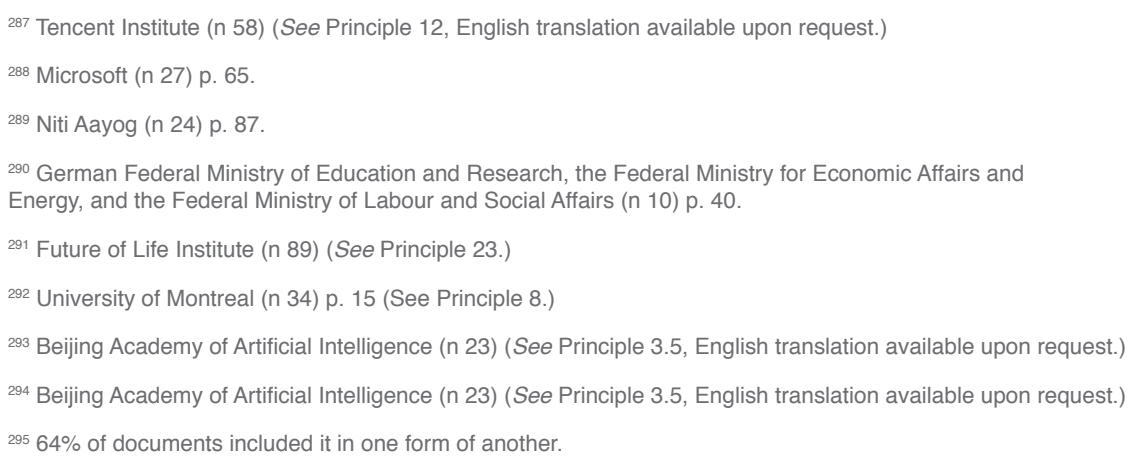




\subsection{Promotion of Human Values}

With the potential of Al to act as a force multiplie for any system in which it is employed, the Promotion of Human Values is a key element of ethical and rights-respecting Al. ${ }^{304}$ The principles under this theme recognize that the ends to which Al is devoted, and the means by which it is implemented, should correspond with and be strongly influenced by social norms. As Al's use becomes more prevalent and the power of the technology increases, particularly if we begin to approach artificial general intelligence, the imposition of human priorities and judgment on $\mathrm{Al}$ is especially crucial. The Promotion of Human Values category consists of three principles: "human values and human flourishing." "access to technology," and "leveraged to benefit society."

While principles under this theme were coded distinctly from explicit references to human rights and international instruments of human rights References to human values and human rights References to human values and human rights were often adjacent to one another, and where the documents provided more specific articulations of human values, they were are largely congruo with existing guarantees found in international human rights law. Moreover, principles that refer to human values often include explicit references to fundamental human rights or international human rights, or mention concepts from human rights frameworks and jurisprudence such as human dignity or autonomy. The OECD and G20 Al principles also add "internationally recognized labor rights" to this list. ${ }^{305}$

\section{PRINCIPLES UNDER \\ THIS THEME}

44\% Human Values and Human Flourishing

$31 \%$ Access to Technology

$64 \%$ Leveraged to Benefit Society

Percentage reflects the number of documents in the dataset that include each principle

There is also an overlap between articulations of the Promotion of Human Values and social, economic, or environmental concepts that are outside the boundaries of political and civil rights, 306 including among documents coded under the principle of Al "leveraged to benefit society." Principle 3, "Make AI Serve People and Planet," from the UNI Global Union's AI principles, is emblematic, calling for: "throughout their entire operational process, Al systems [to] remain compatible and increase the principles of human dignity, integrity, freedom, privacy and cultural and gender diversity, as well as ... fundamental human rights. In addition, Al systems must protect and even improve our planet's ecosystems and biodiversity." ${ }^{30}$

\section{Human Values and Human Flourishing}

The principle of "human values and human flourishing" is defined as the development and use of Al with reference to prevailing social norms, core cultural beliefs, and humanity's best interests. As the Chinese Al Governance Principles put it, this principle means that Al should "serve the progress of human civilization." ${ }^{308}$ This is the broadest of the three principles in the Promotion of Human Values theme and is mentioned in 44 percent of documents. Most documents do not delve especially deeply into what they intend by "human values" beyond references to concepts like self-determination, 309 but the Montreal Declaration contains a somewhat idiosyncratic list calling for Al systems that "permit the grow Ist, calling for Al systems that "permit the grow of the well-being of all sentient beings" by, Inter alla, "help[ing] individuals improve their living conditions, their health, and their working conditions, ... allowing] people to exercise nor mental and physical capacties [and]... not contribut[ing] to increasing stress, anxiety, or a sense of being harassed by one's digital nvironment."

Many of the documents that refer to the theme of "human values and human flourishing" are concerned with how the societal impacts of Al can be managed through Al system design. Tencent's Al principles state that "The R\&D of artificial intelligence should respect human dignity and protect human ights and freedoms." The Smart Dubai Al principles says we should "give Al systems human values and make them beneficial to society," ${ }^{312}$ suggesting that it is possible to build Al systems that have human values embedded in their code. ${ }^{313}$ However, most, if not all, of these documents also acknowledge that human values will also need to be promoted in the implementation of Al systems and "throughout the Al system lifecycle." 314

\section{Access to Technology}

The "access to technology" principle represents statements that the broad availability of $\mathrm{Al}$

technology, and the benefits thereof, is a vital element of ethical and rights-respecting Al. Given the significant transformational potential of $\mathrm{Al}$ documents that include this principle worry that $A$ might contribute to the growth of inequality. The TI Al Policy Principles, a private sector document focus on the economic aspect, stating that "if the value [created by Al] favors only certain incumbe entities, there is a risk of exacerbating existing wage, income, and wealth gaps." ${ }^{15}$ At least one civil society document shares this concern: the T20 report on the future of work and education

WUNI Global Union (n 66) p. 7 (See Principle 3 )

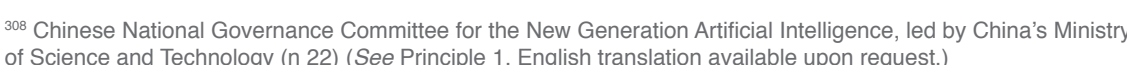
${ }^{\circ 09}$ Think 20 (n 38$)$ p. 7 .

(P) 
avers that "The wealth created by Al should benefit workers and society as a whole as well as the innovators." ${ }^{316}$ The Japanese Al principles, while acknowledging the economic dimension of this issue (observing that "Al should not genera a situation where wealth and social influence are unfairly biased towards certain stakeholders"317), emphasize the sociopolitical dimensions of inequality, including the potential that Al may unfairly benefit certain states or regions as well as contribute to "a digital divide with so-called 'information poor' or 'technology poor' people left behind." 318 Some versions of the "access to technology" access to Al technology itself, as well as the education necessary to use and understand it is the priority. The chin to use and understand it, is provide that "Stak prove that "Stakehor e able to receive education and traning to help nem adapt to the impact of Al development in psychological, emotional and technical aspects. The ITI Al Policy Principles focus on educating and training people who have traditionally been marginalized by or excluded from technologic innovation, calling for the "diversification and broadening of access to the resources necessary for Al development and use, such as computing resources, education, and training." ${ }^{320}$ Two documents, Microsoft's Al Principles and the

\section{${ }^{316}$ Think 20 ( 138 ) p. 7}

si" Japanese Cabinet Office, Council for Sciennce, Technology and Innovation (n 20) p. 9

Sil Japanese Cabinet Office, Council for Sciennce, Technology and Innovation (n 20) p.7.

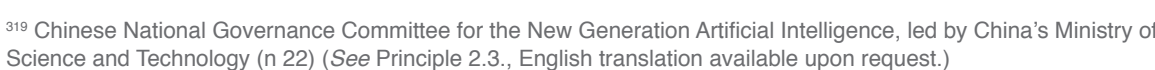

zo Information Technology Industry Council ( 9 9) p. 5 ( See "Democratizing Access and Creating Equality of Opportunity.")

e' European Commission's High-Level Expert Group on Artificial Intelligence (n 6) p. 18

${ }^{322}$ Microsoft (n 27 ) p. 70.

European Commission's High-Level Expert Group on Artificial Intelligence (n 6) p. 11 (See Principle 2.1)

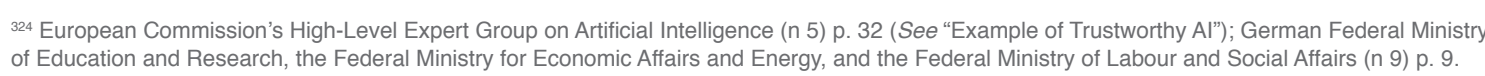

precondition for Al development and use. IEEE's Ethically Aligned Design document uses strong language to assert that it is not enough for $A$ systems to be profitable, safe, and legal; they must also include human well-being as a "primary success criterion for development." "325 Google's Al principles contain a similar concept, stating that the company "will proceed [with the development of Al technology] where we believe that the overal likely benefits substantially exceed the foreseeable risks and downsides" after taking "into account a broad range of social and economic factors." ${ }^{326}$ 


\section{International Human Rights}

In recent years, the human rights community has become more engaged with digital rights, and with the impacts of Al technology in particular. Even outside of human rights specialists, there has been an increasing appreciation for the relevance of international human rights law and standards to the governance of artificial intelligence. ${ }^{327}$ To an area of technology governance that is slippery and fast-moving, human rights law offers an appealingly well-established core set of concepts, against which emerging technologies can be judged. To the broad guarantees of human rights law, principles documents offer a tailored vision of the specific - and in some cases potentially novel - concerns that $\mathrm{Al}$ raises.

Accordingly, when coding the principles documents in our dataset, we also made observations on each document's references to human rights, whether as a general concept or specific human-rights related documents such as the Universal Declaration of Human Rights, International Covenant on Civil and Political Rights, the United Nations Guiding Principles on Business \& Human Rights and the United Nations Sustainable Development Goals. Twenty-three of the documents in our dotaset (64\%) made a reference of this kind Goals. Tw

Given the increasing visibility of $\mathrm{Al}$ in the human rights community and the apparent increasing interest in human rights among those invested in Al governance, we had increasing interest in human rights among those invested in Al governance, we had expected that the data might reveal a trend toward increasing emphasis on human rights in Al principles documents. However, our dataset was small enough, and the

As illustrated in the table below, private sector and civil society documents were most likely to reference human rights. At the outset of our research, we had expected that principles documents from the private sector would be less likely to refer to human rights and government documents more likely. Among the principles documents we looked at - admittedly not designed to be a complete or even representative sample - we were wrong. The actor type with the single greatest proportion of human rights references were the documents from the private sector; only one omitted a reference to human rights. By contrast, less than half of documents authored by or on behalf of government actors did contain some reference to human rights ${ }^{320}$

\begin{tabular}{|l|l|l|l|}
\hline Nature of actor & $\begin{array}{l}\text { Number of } \\
\text { documents }\end{array}$ & \multicolumn{2}{|c|}{$\begin{array}{l}\text { Number with any reference } \\
\text { to human rights }\end{array}$} \\
\hline Civil society & 5 & 4 & $80 \%$ \\
\hline Government & 13 & 6 & $46 \%$ \\
\hline Intergovernmental organization & 3 & 2 & $67 \%$ \\
\hline Multistakeholder initiative & 7 & 4 & $57 \%$ \\
\hline Private sector & 8 & 7 & $88 \%$ \\
\hline Total & $\mathbf{3 6}$ & $\mathbf{2 3}$ & $\mathbf{6 4} \%$ \\
\hline
\end{tabular}

There are multiple possible explanations for this. It may be that the agencies or individuals in government who have been tasked with drafting and contributing to principles documents were not selected for their expertise with human rights law, or it may be that national laws, such as the GDPR, are perceived as more relevant.

The documents also exhibit significant variation in the degree to which they are permeated by human rights law, with some using it as the framework of the whole document (denoted by a star in the data visualization), and others merely mentioning it in passing (denoted by a diamond). Using a human rights framework means that the document uses human rights as a basis for further ethical principle for the development and use of Al systems. Only five documents use a human rights framework. Three are civil society documents and two are government documents from the EU: Access Now report, Al for Europe, European High Level Expert Group guidelines, Public Voice Coalition Al guidelines, and Toronto Declaration. 


\section{Conclusion}

The eight themes that surfaced in this research - Privacy, Accountability, Safety and Security, Transparency and Explainability, Fairness and Non-discrimination, Human Control of Technology, Professional Responsibility, and Promotion of Human Values - offer at least some view into the foundational requirements for Al that is ethical and respectful of human rights. However, there's a wide and thorny gap between the articulation of these high-level concepts and their actual achievement in the real world. While it is the intent of this white paper and the accompanying data visualization to provide a high-level overview, there remains more work to be done, and we close with some reflections on productive possible avenues.

In the first place, our discussion of the forty-seven principles we catalogued should make clear that while there are certainly points of convergence, by no means is there unanimity. The landscape of Al ethics is burgeoning, and if calls for increased access to technology (see Section 3.8) and multistakeholder participation (see Section 3.7) are heeded, it's likely to become yet more diverse. It would be compelling to have closer studies of the variation within the themes we uncovered, including additional mapping projects that might illustrate narrower or different versions of the themes with regard to particular geographies or stakeholder groups. It would also be interesting to look at principles geared toward specific applications of Al, such as facial recognition or autonomous vehicles.

Within topics like "fairness," the varying definitions and visions represented by the principles documents in our dataset layer on top of an existing academic literature, ${ }^{229}$ but also on existing domestic and international legal regimes which have long interpreted these and simitc and in lition technology is still nascent, with just a handul of cases having been brought. Similarly, tech many of the docums in aur dataset anticipate, and even explicitly call for (see Sections 3.1 and 3.2) in our dataset anticipate, and even explcilly call for (see sections 3.1 and 3.2), such actions. Tracking how principles documents engage with and in fluence how labity for Al-related damages is apportioned by courts, legislatus,

There will be a rich vein for further scholarship on ethical and rights-respecting Al for some time, as the norms we attempt to trace remain actively in development. What constitutes "Al for good" is being negotiated both through top-down efforts such as dialogues at the intergovernmental level, as well as bottom-up, among people most impocted by the dit impacted by the deploym work of the many individuals and organizations who are participating in them, and werd are proud to play our part. 


\section{Bibliography}

Access Now, 'Human Rights in the Age of Artificial Intelligence' (2018) <https://www. accessnow.org/cms/assets/uploads/2018/11/Al-and-Human-Rights.pdf>

Amnesty International, Access Now, 'Toronto Declaration: Protecting the Right to

Equality and Non-Discrimination in Machine Learning Systems' (2018) <https://www. pdf>

Artificial Intelligence Industry Alliance, 'Artificial Intelligence Industry Code of Conduct (Consultation Version)' (2019) <https://www.secrss.com/articles/11099>

Beijing Academy of Artificial Intelligence, 'Beijing Al Principles' (2019) <https://www. baai.ac.cn/blog/beijing-ai-principles?categoryld=394>

British Embassy in Mexico City, 'Artificial Intelligence in Mexico (La Inteligencia Artificial En México)' (2018) <https://docs. wixstatic.com/ugd/7be025

ba24a518a53a4275af4d7ff63b4cf594.pdf $>$

Chinese National Governance Committee for the New Generation Artificial Intelligence, led by China's Ministry of Science and Technology 'Governance Principles for a New Generation of Artificial Intelligence: Develop Responsible Artificial Intelligence' (2019)

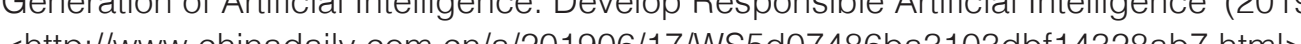

Council of Europe, European Commission for the Efficiency of Justice, 'European Ethical Charter on the Use of Artificial Intelligence in Judicial Systems and Their Environment' (2018) <https:///rm.coe. int/ethical-charter-en-for-publication-4-december2018/16808f699c>

European Commission, 'Artificial Intelligence for Europe: Communication from the Commission to the European Parliament, the European Council, the Council, the
European Economic and Social Committee, and the Committee of the Regions' COM European Economic and Social Committee, and the Committee of the Regions' COM (2018) $237<$ <https://ec europa.eu/digital-single-market/en/news/communication-artfificiaintelligence-europe>

European Commission's High-Level Expert Group on Artificial Intelligence, 'Ethics Guidelines for Trustworthy Al' (2018) <https://ec.europa.eu/digital-single-market/en/ news/ethics-guidelines-trustworthy-ai>

Future of Life Institute, 'Asilomar Al Principles' (2017) <https://futureoflife.org/aiprinciples/?cn-reloaded $=1>$
G20 Trade Ministers and Digital Economy Ministers, 'G20 Ministerial Statement on Trade and Digital Economy' (2019) <https://www mofa go jp/files/000486596 pdf>

German Federal Ministry of Education and Research, the Federal Ministry for Economic Affairs and Energy, and the Federal Ministry of Labour and Social Affairs, 'Artificial Intelligence Strategy' (2018) <https://www.ki-strategie-deutschland.de/home.html>

Google, 'Al at Google: Our Principles' (2018) <https://www.blog.google/technology/ai/ ai-principles/>

IA Latam, 'Declaración de Principios Éticos Para La IA de Latinoamérica' (2019) <http:// ia-latam.com/etica-ia-latam/>

IBM, 'IBM Everyday Ethics for Al' (2019) <https://www.ibm.com/watson/assets/duo/pdf/ everydayethics.pdf>

IEEE Global Initiative on Ethics of Autonomous and Intelligent Systems, 'Ethically Aligned Design: A Vision for Prioritizing Human Well-Being with Autonomous and Intelligent Systems' (2019) First Edition <https://ethicsinaction ieee org/>

Information Technology Industry Council, 'Al Policy Principles' (2017) <https://www itic. org/resources/Al-Policy-Principles-FullReport2.pdf>

Japanese Cabinet Office, Council for Science, Technology and Innovation, 'Social Principles of Human-Centric Artificial Intelligence' (2019) <https://www8.cao.go.jp/cstp/ english/humancentricai.pdf>

Microseft 'Al Principles' (2018)<htps.//www microsoft.com/en-us/ai/our-approach-toai>

Mission assigned by the French Prime Minister 'For a Meaningful Artificial Intelligence: Toward a French and European Strategy' (2018) <https://www.aiforhumanity.fr/pdfs/

Monetary Authority of Singapore, "Principles to Promote Fairness, Ethics, Accountability and Transparency (FEAT) in the Use of Artificial Intelligence and Data Analytics in Singapore's Financial Sector' (2019) <http://www.mas.gov.sg/ /media/MAS/News\%20 and\%20Publications/Monographs\%20and\%20Information\%20Papers/FEAT\%20 Principles\%20Final.pdf>

New York Times' New Work Summit, 'Seeking Ground Rules for Al' (March 2019) <https://www_nytimes com/2019/03/01/business/ethical-al-recommendations html> 
Niti Aayog, 'National Strategy for Artificial Intelligence: \#Al for All (Discussion Paper)' (2018) <https://www.niti.gov.in/writereaddata/files/document_publication/ NationalStrategy-for-Al-Discussion-Paper.pdf>

Organisation for Economic Co-operation and Development, 'Recommendation of the Council on Artificial Intelligence' (2019) <https://legalinstruments.oecd.org/en/ instruments/OECD-LEGAL-0449>

Partnership on Al, 'Tenets' (2016) <https://www.partnershiponai.org/tenets/>

Smart Dubai, 'Artificial Intelligence Principles and Ethics' (2019) <https://smartdubai.ae/ initiatives/ai-principles-ethics>

Standard Administration of China, 'White Paper on Artificial Intelligence Standardization' excerpts in English published by New America (January 2018) <https://www.

newamerica org/cybersecurity-initiative/digichina/blog/translation-excerpts-chinas-whitepaper-artificial-intelligence-standardization/>

Telefónica, 'Al Principles of Telefónica' (2018) <https://www.telefonica.com/en/web/ responsible-business/our-commitments/ai-principles>

Telia Company, 'Guiding Principles on Trusted Al Ethics' (2019) <https://www.

teliacompany/com/alobalassets/telia-company/documents/about-telia-company/publicpolicy/2018/guiding-principles-on-trusted-ai-ethics.pdf>

Tencent Institute, 'Six Principles of Al' (2017) <http://www.kejilie.com/iyiou/article/ ZRZFn2.html>

The Public Voice Coalition, 'Universal Guidelines for Artificial Intelligence' (2018) $<$ <ttps://thepublicvoice.org/ai-universal-guidelines/>

Think 20, 'Future of Work and Education for the Digital Age' (2018) <https://www.g20insights.org/wp-content/uploads/2018/07/TF1-1-11-Policy-Briefs_T20ARG_Towards-aG20-Framework-For-Artificial-Intelligence-in-the-Workplace.pdf>

UK House of Lords, Select Committee on Artificial Intelligence, 'Al in the UK: Ready, Willing and Able?' (2018) Report of Session 2017-19 <https://publications.parliament.uk/ pa//d201719//dselect//dai/100/100.pdf>

UNI Global Union, ‘Top 10 Principles for Ethical Artificial Intelligence' (2017) <htpp// www.thefutureworldofwork.org/media/35420/uni_ethical_ai.pdf>
United States Executive Office of the President, National Science and Technology Council Committee on Technology, 'Preparing for the Future of Artificial Intelligence' (2016) <https://obamawhitehouse.archives.gov/sites/default/files/whitehouse_files/ microsites/ostp/NSTC/preparing_for_the_future_of_ai.pdf>

University of Montreal, "Montreal Declaration for a Responsible Development of Artificial Intelligence' (2018) <https://www.montrealdeclaration-responsibleai.com/thedeclaration> 
cyber.harvard.edu 